\title{
Parameter Determination for A Numerical Approach to Undeveloped Shale Gas Production Estimation: The UK Bowland Shale Region Application \\ Ukadike Nwaobi* and Gabrial Anandarajah ${ }^{1 *}$
}

\begin{abstract}
The estimation of production potential provides the foundation for commercial viability appraisal of natural resources. Due to uncertainty around production assessment approaches in the unconventional petroleum production field, an appropriate production estimation methodology which address the requisite uncertainty at the planning stage is required to guide energy policy and planning. This study proposes applying the numerical unconventional production estimation method which relies on geological parameters, (pressure, porosity, permeability, compressibility, viscosity and the formation volume factor) as well as the rock extractive index (a measure of technical efficiency). This paper develops a model that estimates the appropriate values for four of these parameters based on a depth correlation matrix while a stochastic process guides two based on known data range. The developed model is integrated with a numerical model to estimate gas production potential. The developed framework is eventually applied to undeveloped shale gas wells located in the Bowland shale, central Britain. The results account for below ground uncertainty and heterogeneity of wells. A sensitivity analysis is applied to consider the relative impacts of individual parameters on production potential. The estimated daily initial gas production rate ranges from 15,000scf to 319,000scf while estimated recovery over 12 years is approximately $1.1 \mathrm{bscf}$ in the reference case for wells analyzed.
\end{abstract}

Key words: Unconventional Gas, Production Analysis, Production Forecast, Estimated Ultimate Recovery, Parameter Determination

\section{Introduction}

Well evaluation and its decline characteristics are fundamental to decision making in the petroleum industry; estimating recoverable cost-effective hydrocarbon reserves is of utmost importance to engineers, investors and policy makers (Statton, 2012). However, the recoverable reserve uncertainty creates a challenge for both policymakers and investors appraising the commercial viability of shale gas plays. The estimated ultimate recovery (EUR) is among the most contested topic amongst petroleum industry experts (Baihly et al., 2010). HoL (2014) concludes that the economic benefits of unconventional gas development cannot be quantified without knowledge of the EUR. The early phase of shale gas development is uncertain and risky due to limited knowledge of the EUR (Weijermars 2013). Zou et al., (2016) highlights shale gas resource assessment challenges to be typified by large uncertainties as well as complex geological, petrophysical and geochemical factors. Yuan et al., (2015), based on statistics and analyses, states that there only few studies available that address input parameter prediction

*UCL Energy Institute, University College London, Central House, 14 Upper Woburn Place London; ${ }^{1}$ Corresponding author, Email: g.anandarajah@ucl.ac.uk 
issues for shale gas development. Nwaobi and Anandarajah (2018) reviews production analyses and estimation methods applied in shale gas fields and plays; the study infers that most methods are unsuitable for undeveloped gas wells due to their inability to account for below ground risk at the early stage, reservoir heterogeneity and reservoir parameter uncertainty.

This study makes a pioneering attempt to apply the analytical production appraisal model to undeveloped shale wells in various ways. Firstly, as the parameters that drive the analytical model are currently not available for an undeveloped well, we establish the characteristics boundaries and then determine the required parameters. Secondly, uncertainty is accounted for by conducting a sensitivity analysis and applying a stochastic process to simulate, estimate some parameters and provide insight. Consequently a hybrid simulation scenario is developed which applies both deterministic and probabilistic modelling concepts to production estimation in shale gas wells. The hybrid model enables the incorporation of the merits of both deterministic and probabilistic methods. Finally, the conceptual framework is applied to the Bowland shale region located in central Britain; generating production profiles based on the developed model scenarios.

The outline of this study is as follows; following the Introduction, Section II assesses the case study undeveloped shale play: the UK Bowland. Section III reviews literature in production estimation methodologies; merits and drawbacks. Section IV proposes an alternative approach for undeveloped shale gas wells, below ground parameter impact are analysed all on a per well basis. Section V provides details of the results which are analysed with a focus on benefits and drawbacks of the approach. Finally, conclusions and recommendations are offered based on the methodology and results provided by the study in Section VI.

\section{An Undeveloped Unconventional Play: The UK Bowland Case}

\subsection{Introduction}

Shale gas resources were accidentally discovered in the UK about 137 years ago (Selley, 2012). Studies (Selley 1987, 1992, and 2005) focused on evaluating the United Kingdom's (UK) shale gas resources since 1987. However, results did not initiate unconventional gas exploration; this could be associated to its cost effectiveness in comparison with the UK continental shelf (UKCS). The UKCS comprises areas of the sea bed and subsoil beyond the territorial sea over which the UK exercises sovereign rights of exploration and exploitation of natural resources around the North Sea.

A study by the Department of Energy and Climate Change (DECC) aimed to determine the potential of the UK's unconventional gas resources reveals current interest is based on the US experience 
(DECC 2011). In addition, the study, based on analogues due to lack of exploration activity, estimates $30 \mathrm{bcf}$ for the Jurassic shale play, $2.1 \mathrm{tcf}$ for the carboniferous play and $300 \mathrm{bcf}$ for the Cambria shale gas play. The US Energy Information Agency report using a resource assessment methodology, estimates the technically recoverable shale gas resource for the UK as 26 tcf not taking into account the Cambria shale gas play due to lack of applicable data (US EIA, 2013).

\subsection{The Carboniferous Bowland Shale Gas}

The carboniferous Bowland shale formation is located in central Britain and considered to be a proven source of matured rock for gas production (Smith et. al., 2010, DECC, 2011). The Bowland Shale formation is the most prospective shale gas play on a regional level (Smith et al., 2010). It is bounded by complete erosion of the potentially prospective shales over highs to the south, by uplift in several areas where the prospective units are at outcrop, and by a facies-change in the north and north-east to contemporary deltaic deposits (Andrew, 2013). The Shale formation comprises of mudstone and turibidite lithofacies reflecting a pronounced sea level controlled cyclicity (Gross et al., 2015).

Andrew (2013) applies a 3D geological model as an input parameter in a Monte Carlo simulation to predict the preliminary gas in place by dividing the play into two units an upper and lower unit, with the upper Bowland-Hodder unit estimated to have with a gas in place range of 164-264-447 tcf while the lower unit is estimated to possess a gas in place range of 658-1065-1834tcf; results are presented in low, central and high scenarios. McGlade (2013) notes that the gas in place is the largest resource potential figure, however, the figure conveys incomplete information needed for estimating recoverable resources. The EUR of a region, field, play or well is considered as the total amount of gas or oil recoverable over time while the technical recoverable reserves refers to recovery ability based on the existing applied technology. Although previous studies have defined the gas in place in the Bowland shale play however

the estimated ultimate recovery has not been appraised and thus the commercial viability or energy security implications of developing the play remains uncertain. This study applies the developed integrated methodology to estimate production from wells located in the Bowland shale basin.

\section{Literature Review on Shale Gas Recoverable Resource Analysis and Estimation Methods}

Well evaluation and decline characteristics are fundamental to decision making in the petroleum industry (Nwaobi and Anandarajah, 2018). EURs and initial production are considered to be two parameters that define commercial viability in a play (Kaiser, 2012). This review groups production analysis and estimation methods applied in shale gas resource assessment into three categories; empirical, type curves and numerical methods. 


\subsection{Empirical Method}

The empirical based approach which is also referred to as decline curve analysis, seeks to outline hydrocarbon well initial production rate percentage decrease over time (Clark, 2011). The empirical theory provided the foundation for reservoir production analysis and estimation initiated by Arps's (1944) which identified three production rate scenarios; exponential, hyperbolic and harmonic. The Arps model assumes constant bottom-hole pressure, boundary dominated flow, unchanged drainage area and a constant skin factor (Fetkovich, 1996). However unconventional wells have been observed with uncharacteristic production rate scenarios which when applied to Arp's model yield unrealistic infinite reserves (Lee and Sidle, 2010). Additionally, Clark (2011) notes that most of the assumptions on which Arp's model is based, especially the flow regime and drainage area, are inapplicable to undeveloped plays. Therefore, researchers in this field apply different approaches such as extending the empirical approach (Valko and Lee, 2010; Ilk et al., 2008; and Kanfar, 2013), the stretched exponential behaviour theory (Valko and Lee, 2010), the power loss ratio rate (Ilk et al., 2008), and the logistic growth method (Kanfar, 2013). Weijermars (2013) applies a decline curve analysis in estimating gas production from undeveloped unconventional sources in Europe. Weijermars (2014 \& 2015) employ a decline function as well as Arps formula assuming an exponential decline; using similar recovery factors for different shale plays. Applying similar recovery factors to different plays and different countries neglects the peculiarity of shale gas wells. Additionally, Nwaobi and Anandarajah (2018) note that the major limitation associated with the decline method is the need to assume a decline trend as well as its inability to account for reservoir conditions and its heterogeneity. Yuan et al (2015) also comments that existing production methods are inaccurate due to lack of knowledge concerning decline curves due to short shale gas production history. Chen et al., (2015) equates the application of a single decline curve for an entire shale play to a random drilling process which leads to economic estimation susceptible to severe variations across a shale play.

\subsection{Type Curve Methods}

Type curves are an alternative unconventional hydrocarbon production analysis and estimation model which like the empirical method depends also on historical production data fitted to flow equations but corresponding to different "types" of well geometry, reservoir and boundary conditions. The methodology has been applied to both production forecasting and reservoir characterization for over 70years (Ilk et al., 2007). Fetkovich (1980) created type curves by combining Arps' empirical decline curves for boundary dominated flow and analytical solutions for constant flowing pressure radial flow for liquids (Clarkson, 2013). Fetkovich et al., (1987) upgraded type curves to consider gas production. Consequently, Blasingame and Palacio (1993), introduced a type curve method developed for both oil 
and gas field which considers variation in the production rate and pressure. Wattenbarger et al., (1998) and Agrawal (1999) also develop type curves as well as Nobakht and Mattar (2012) and Clarkson et al., (2012) addressing and incorporating previously ignored effects and variables. Williams- Kovacs \& Clarkson (2011) apply a type curve in production forecast for an undeveloped prospect while Gray et. al., (2007) and Kaiser (2012) use the approach in the analysis of a developed shale play. Nevertheless, Nwaobi and Anandarajah (2018) notes that reservoir type assumption requirement is a challenge for nontechnical analysts and policy makers applying type curves in production evaluation.

\subsection{Numerical Methods}

The third appraised unconventional gas production estimation method known as analytical/numerical approach has its foundation based on the physics of fluid flow and storage. Lee et al., (2003) states that numerical models are logically derived mathematical solutions. Furthermore Clarkson (2013) notes that analytical models are based on simple reservoir characteristics and boundary conditions. Vera and Ehlig-Economides, (2014) and Wang (2013) both apply numerical models to unconventional gas production estimation including reservoir completions details. Patzek et al., (2013) proposes the rock extractive index(REI); an analytical model developed by extending a mathematical model which incorporates hydrocarbon phase characteristics, a scaling function and two adjustable parameters for each well. Gulen et al. (2013 \& 2014) as well as Browning et al., (2013) apply the approach to different developed and producing shale regions. Medlock (2012) analyses 16,000 wells production panel data which provides empirical evidence that supports this analytical model. Nwaobi and Anandarajah (2018) suggest that the REI model is adaptable by technical, non-technical policy makers and analysts. The model can be used to account for changes in pressure and reservoir. Nonetheless the numerical method is based on theoretical empirical reservoir conditions which could be invalidated by future unconventional reservoirs and requires additional data and parameters.

\subsection{Limitation of Current Methods}

Shale gas production model application could be assessed based on shale play development stage (undeveloped or developed play), ability to account for uncertainty and heterogeneity (Nwaobi and Anandarajah, 2018). Applying empirical models in the production analysis as well as estimation of undeveloped shale plays requires fitting historical production data and assumed average EURs an approach that can be termed top bottom. McGlade et al., (2013) advocates a bottom up analysis of geological parameters for undeveloped shale plays rather than top bottom approaches based on extrapolation of production experience. Taylor (2013) assumes hyperbolic decline and factor; Weijeimars (2013) assumes exponential decline, average EUR/well from Kuhn and Umbach (2011) as 
well as production rates. Alternatively applying analytical models requires geological and reservoir parameters, which may be unavailable in the case of undeveloped shale gas plays. In some cases when available, Andrews (2013) notes that source rock geological parameters are often not publicly available; in the United Kingdom under onshore license terms, well data available to regulators are confidential for four to five years.

Production forecast in unconventional gas that leads to reserve booking should be achieved via analytical methods (Clarkson et al., 2012). There is limited research that addresses input parameter estimation methods for shale gas development (Yuan et al. 2015). Nwaobi and Anandarajah (2018) suggest the extension of current analytical methods via stochastic or correlation analysis of reservoir parameters for undeveloped shale gas prospects; which avoids the highlighted limitations associated with type and decline curves; leads to proper review of energy resource investments appraisal, perceived energy security contributions and sustainability criteria. As such the need for a parameter determination method which extends current analytical models for production estimation is required. Consequently, Nwaobi and Anandarajah (2018) proposed developing a correlation model based on available data but also acknowledge the difficulty and uncertainty associated with reservoir characterization. Uncertainty in petroleum economic analysis can be termed below and above ground uncertainties. The below ground uncertainty relates to reservoir properties while above ground relates to the economic and commercial conditions (Gas Prices, Costs, Fiscal Regimes, Production scenarios). Researchers in this field (Kaiser, 2012; Gulen et al., 2013; Taylor, 2013; Weijermars, 2013) consider above ground risk while neglecting below ground uncertainty. The primary advantage of analytical methods is the ability to reveal production forecast scenarios based on uncertainty of key reservoir properties (Clarkson et al. 2013). In relation to heterogeneity, McGlade et al., (2013) and USEIA (2013), both attest to unconventional gas wells being heterogeneous which is attributed to source rock diversity (Cipolla and Ganguly 2012). Gulen et al., (2013 and 2014) both support the heterogeneous nature of shale gas fields by revealing different production profiles based on individual well analysis. On the contrary, Taylor (2013) and Weijermars (2013) apply decline and type curves to entire countries and regions based on average EUR/wells; an approach that neglects the heterogeneity of unconventional gas wells. In a more recent study, Weijermars (2015) highlights the heterogeneity of shale gas well; each well is considered a new reservoir itself with inherent geological uncertainty.

The review concludes that the production analysis and estimation of undeveloped unconventional gas reservoirs based on empirical, type curves and numerical models in their present form ignores established well characteristics thus making them impractical for economic analysis of undeveloped 
unconventional wells; their impracticality results from the absence of production and drilling data which could be used to develop decline and type curves. This paper aims to develop a parameter estimation model which can be integrated to a numerical approach applicable to a prospective shale gas play. The numerical approach is chosen for our study since it does not depend on the EUR; which is not available for an undeveloped play and the method analysis on a per well basis; accounting for reservoir distinctiveness. This study applies the REI model derived from the study of over 20,000 individual wells across three shale plays in the United States. The method relies on the originated relationship of the well geology, gas properties, physics and drainage area; the parameters. These parameters are highly uncertain in the undeveloped phase of shale gas wells. Consequently this study aims to develop an innovative theoretical framework that focuses on the input parameters that dictate shale gas production based on the REI model. A 2017, USEIA study on the distribution of US oil and gas wells (primarily shale wells) production rate notes that subsurface geology is among the most important component that defines play success (USEIA, 2017).

\section{Approach}

An analytical model which accounts for heterogeneity and below ground uncertainty is proposed. However due to reservoir data unavailability the analytical model in its present form cannot be applied; as such a parameter correlation model is proposed to estimate reservoir parameters. This section reveals the proposed approach based on an existing analytical model, identifies the applicable ranges for parameters via literature review and develops a parameter correlation matrix based on the depth of the reservoir. The methodology is based primarily on a developed Depth Dependent Correlation Matrix (DDCM) as well as an existing well production estimation model. The DDCM estimates the unavailable input parameters applied to the production estimation Model. The integration of the models yields the production estimate for an undeveloped unconventional gas wells.

\subsection{Depth Dependent Correlation Matrix (DDCM)}

The parameter estimation model is developed based on depth correlations as well as standard reservoir equations assuming ideal gas to estimate unknown parameters. Figure 1 shows the derivation process as well correlations which drive the developed depth dependent correlation matrix. The matrix aims to estimate pressure, compressibility, formation volume factor and viscosity. The data presented in table 1 below reveals the reservoir depths applied to the DDCM process in Figure 1. 


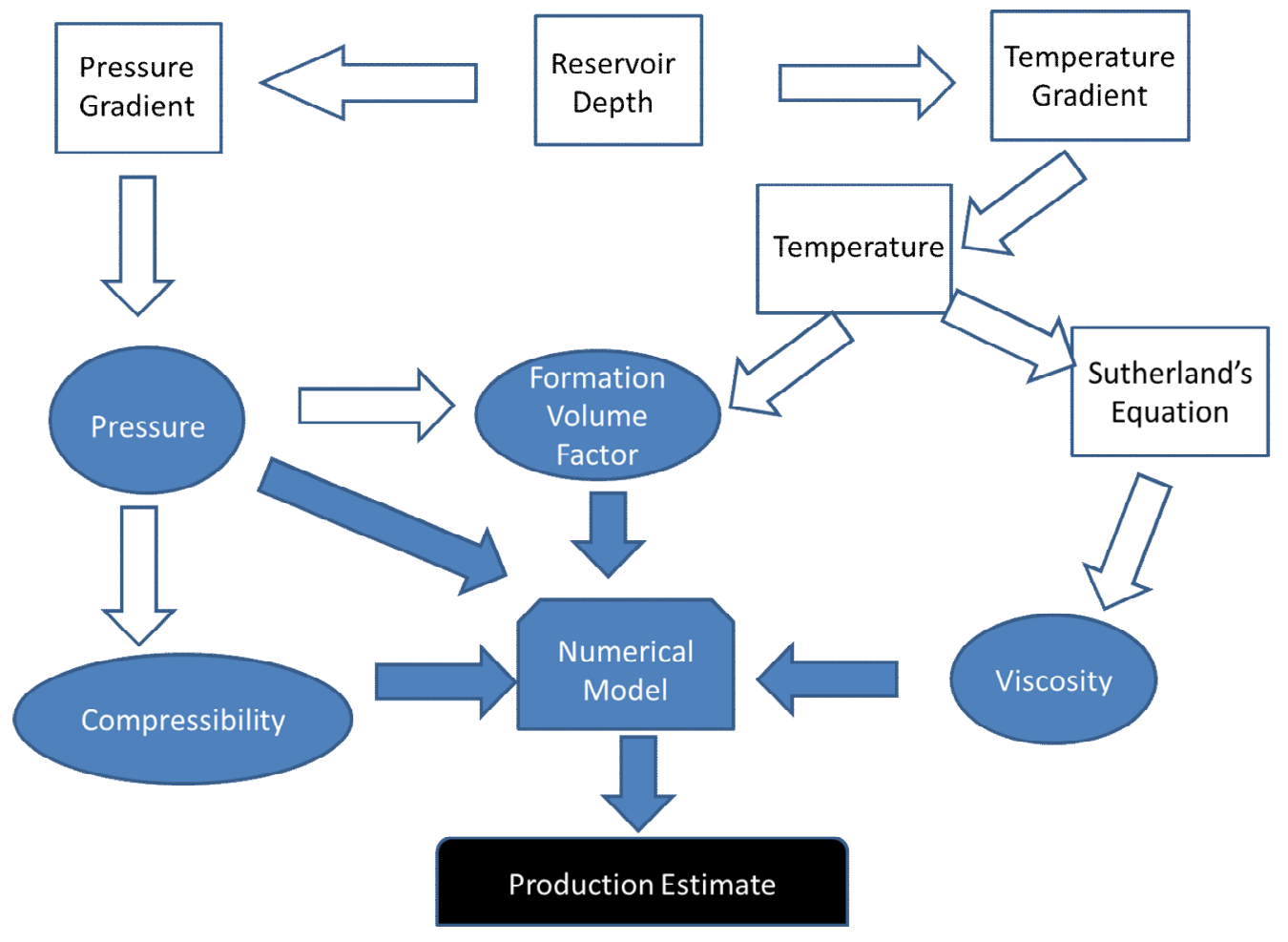

Figure 1 Schematic Representation of the DDCM Process

The Depth Dependent Correlation Matrix process flow highlighted above commences with the reservoir depth which has a relationship with pressure and temperature via gradients. The well pressure is an applied parameter to the numerical model but also contributes to yielding other direct parameters; compressibility and formation volume factor which similarly depend on the estimated temperature. Asides the input of estimated temperature on formation volume factor, temperature also supports the valuation of viscosity; a required numerical model input parameter.

Table 1 Well Depth Data (Source: Smith et al., 2010)

\begin{tabular}{|c|c|}
\hline Well Name & Depth $\left(\mathbf{f t}^{\mathbf{2}}\right)$ \\
\hline Blacon East & 7431.80 \\
\hline Bosley & 6568.00 \\
\hline Grove Well & 7564.60 \\
\hline Heywood Well & 5260.00 \\
\hline Long Eaton & 5901.00 \\
\hline Roddlesworth & 4226.00 \\
\hline Swinden & 2038.00 \\
\hline Wessesnden & 3505.00 \\
\hline
\end{tabular}




\subsection{Unconventional well production model}

The rock extractive index, a pressure transient analytic method is based on equation 1 .

$\boldsymbol{q}=\frac{\mathbf{2}}{\sqrt{\boldsymbol{\pi}\left(\sqrt{\boldsymbol{K}} \phi \frac{\boldsymbol{c}}{\boldsymbol{\mu}}\right)}} \boldsymbol{A} f / B g(\Delta p / \sqrt{t}) \ldots \ldots \ldots . .$. Equation 1

Where $q$ represents flowrate, $K$ rock permeability, $\emptyset$ is rock porosity, $c$ is compressibility, $\mu$ is natural gas viscosity, $A f$ is area of rock exposed by the hydraulic fracture (Rock Exposure Index), $B g$ is formation volume factor, $p$ is gas pressure and $\Delta \mathrm{p}$ is pressure between reservoir and fracture pressure (assumed as 500psi) while $\mathrm{t}$ is time in months.

\subsection{Reservoir Parameter boundaries for unconventional gas wells}

Gas wells both conventional and unconventional possess characteristic range of value for permeability, porosity, isothermal compressibility, viscosity, formation volume factor and pressure based on other factors. A detailed literature review on reported values for each parameter results are in Table 1. Specific parameter distributions data is unavailable in undeveloped unconventional wells. The reservoir parameter boundaries are hence necessary to establish the appropriate model framework and provide validation based on empirical evidence. Kaiser (2012) notes that parameter distribution is less important than including all relevant variables within their expected ranges while developing a modelling framework.

Table 2 Parameter boundaries

\begin{tabular}{|c|c|c|c|c|c|}
\hline Parameter & Symbol & $\begin{array}{l}\text { Minimum } \\
\text { Value }\end{array}$ & $\begin{array}{l}\text { Maximum } \\
\text { Value }\end{array}$ & Units & Source \\
\hline $\begin{array}{l}\text { Rock } \\
\text { Permeability }\end{array}$ & $\mathrm{K}$ & $1.00 \mathrm{E}-6$ & $1.00 \mathrm{E}-1$ & $\mathrm{mD}$ & $\begin{array}{l}\text { Cipolla et al.,2010; Wang et } \\
\text { al.,2013 }\end{array}$ \\
\hline Rock Porosity & $\Theta$ & 0.5 & 9 & $\%$ & $\begin{array}{l}\text { Cipolla et al.,2010; Wang et } \\
\text { al.,2013; Lee et al., } 2011\end{array}$ \\
\hline $\begin{array}{l}\text { Compressibilit } \\
\text { y }\end{array}$ & $\mathrm{C}$ & 0.0001015 & 0.201 & $\mathrm{Psi}^{-1}$ & $\begin{array}{l}\text { Fateke, 2008; Bingxiang et al. } \\
\text { 2013; Wang et al. } 2013\end{array}$ \\
\hline Gas Viscosity & $\mu$ & 0.301 & 0.0101 & $\mathrm{cp}$ & $\begin{array}{l}\text { Sepehrnoor et al.,2013; Bingxiang } \\
\text { et al.,2013; Cander, } 2012\end{array}$ \\
\hline $\begin{array}{l}\text { Formation } \\
\text { Volume Factor }\end{array}$ & $\mathrm{B}_{\mathrm{g}}$ & 0.01 & 0.003 & Rcf/scf & $\begin{array}{l}\text { McCain W.D, 1990;Bingxiang et } \\
\text { al.,2013 }\end{array}$ \\
\hline Pressure & $\mathrm{P}$ & 300 & 4000 & psi & $\begin{array}{l}\text { Curtis, 2002; USEIA, } \\
\text { 2013;Cipolla and Ganguly , } 2012\end{array}$ \\
\hline
\end{tabular}

*Central values are averages. 
1) Pressure

The hydrostatic pressure is assumed based on USEIA (2013), and Andrew (2013); the depth dependent correlation matrix commences applying hydrostatic pressure gradient equation 2 below to estimate the reservoir pressure.

$$
\mathrm{P}=0.433 p s i * \text { Reservoir Depth per Foot..............Equation } 2
$$

Reservoir temperature is also derived using depth versus temperature gradient equation 3 below

$$
1.25 F=100 \text { feet depth........Equation } 3
$$

2) Viscosity

The resultant temperature $(T)$ is applied to the Sutherland. Equation 4 below has been used to estimate viscosity

$$
\mu=\mu o *(a / b) *(T / T o)^{(3 / 2) \quad \ldots \ldots \ldots \ldots \ldots \ldots \ldots \ldots \ldots . . . . . . . . . . . . . . . . . u a t i o n ~} 4
$$

Where

$\mu=$ Viscosity in Centipoise at input temperature

$\mu_{\mathrm{o}}=$ Reference Viscosity in centipoise at reference temperature

$\mathrm{T}=$ Input Temperature

$\mathrm{T}_{\mathrm{o}}=$ Reference Temperature

$$
\begin{aligned}
& a=0.555 T o+C \ldots \ldots \ldots \ldots \ldots \ldots . . . \ldots \text { Equation } 5 \\
& b=0.555 T+C \ldots \ldots \ldots \ldots \ldots \text { Equation } 6
\end{aligned}
$$

$\mathrm{C}=$ Sutherland's Constant

Natural Gas specific gravity of 0.75 is assumed (Lide, 2005; Durst, 2008; Crane, 1988; CRC, 1984)

\section{3) Compressibility}

Compressibility $(\mathrm{C})=1 / \mathrm{P}$ (assuming an ideal gas property). Pressure $(\mathrm{P})$ from equation 2 above

\section{4) Formation Volume Factor}

The formation volume factor is estimated below

$$
B g=0.02829\left(\frac{Z(T)}{P}\right) \ldots \ldots \ldots \ldots \ldots \ldots \text { Equation } 7
$$

$\mathrm{Bg}=$ Formation Volume Factor 
$\mathrm{Z}=$ Compressibility factor (assumed as 0.8). T \& $\mathrm{P}$ are based on equation 2 and 3 above (Dake, 1998; USEIA, 2013).

Parameter ranges for porosity and Permeability; High, Mid and Low values are applied alongside the other DDCM derived parameters into the numerical model to generate corresponding production scenarios.

\section{Hybrid Approach}

The hybrid approach is necessitated to address the high uncertainty introduced into the production estimation by the absence of porosity and permeability values in an undeveloped shale gas well. This lack of empirical evidence also impacts the first step and requirement to propose a distribution characteristic. Consequently the uniform and normal distribution outlines are applied in this approach; the characteristic high and low values are thus interpreted as either the maximum and minimum values.

A risk analysis using a Monte Carlo simulation is applied to randomly estimate the value of porosity and permeability for both the log normal and uniform distributions using the @ Risk software by Palisade. The random sampling and selection process requires a large number of iterations; we use $5 \times 10^{3}$ over 100 times. The results yield the most probable values for these parameters under these distributions.

\section{Lateral Length Evolution}

The REI which represents the area of the rock exposed by the hydraulic fracturing is considered to relate to the efficiency of the hydraulic fracturing. The REI value is assumed as $1 \%$ of lateral length. However lateral has progressed from an average value of $3500 \mathrm{ft}^{2}$ to a $7500 \mathrm{ft}^{2}$ between 2013 and 2016(USEIA, 2016). The impact of lateral length progression over time in shale gas well production profile is also analysed.

\section{Results}

\section{A. Parameter Determination}

The result presented in Table 3 from the DDCM represents the estimated input parameter values for the Blacon East well. Furthermore, Table 3 develops production scenarios applied to the numerical model based on parameter boundaries in rock permeability and porosity data from Bowland shale prospect $^{1}$. The validation of the resultant parameter values is based on reference to established ranges

\footnotetext{
${ }^{1}$ Smith et. al., 2010 provides porosity and permeability data range for the Bowland Shale Play
} 
from literature founded on over 20years of shale gas well study as presented in table 2. Furthermore in terms of the DDCM's validation, the results in table 3 below reveals a pressure estimate of 3218psi; Viscosity, 0.0126cp ; Formation Volume Factor, $0.001 \mathrm{Rcf} / \mathrm{Scf}$ and compressibility. These results are all within the established range for these parameters in table 2 above based empirical shale gas study results. The parameter ranges are characteristic to shale gas wells; all determined values from the DDCM are thus in conformity.

Table 3 Results from the Depth Driven Correlation Matrix (DDCM) for Blacon East Well

\begin{tabular}{|c|c|r|}
\hline Parameter & Value & Unit \\
\hline Pressure & 3218 & $\mathrm{psi}$ \\
Viscosity & 0.0126 & $\mathrm{cp}$ \\
Formation Volume & 0.001 & $\mathrm{Rcf} / \mathrm{scf}$ \\
Factor & & \\
Compressibility & 0.0003 & $\mathrm{Psi}^{-1}$ \\
\hline
\end{tabular}

Table 4 Permeability and Porosity Values Applied In Scenarios

\begin{tabular}{|c|c|c|c|c|}
\hline Parameter & $\begin{array}{c}\text { Low Case } \\
\text { Value }\end{array}$ & $\begin{array}{c}\text { Mid } \\
\text { Case } \\
\text { Value }\end{array}$ & $\begin{array}{c}\text { High } \\
\text { Case } \\
\text { Value }\end{array}$ & Unit \\
\hline Permeability & 0.00000443 & 0.00355 & 0.0071 & $\mathrm{mD}$ \\
Porosity & 3 & 6.5 & 10 & $\%$ \\
\hline
\end{tabular}

\section{B. Production Estimation}

The production estimates are for over twelve years with below ground parameter uncertainty establishing production scenarios. The three profiles per well highlighted by our results are lower, median and high production case scenarios. A review of the production profiles indicates that on average $50 \%$ of production is achieved within the first six years while production peaks in the second or third production month.

An appraisal of Figures 2-6, shows that the Blacon east, Bosley, Long Eaton and Heywood wells have high possibility to produce relatively higher volumes of gas amongst the wells analysed; the three wells provide $80 \%$ of estimated recoverable reserve (Figure 7). The average daily production of the six wells in the study area Bowland shale is $147,718.64 \mathrm{scf}$ based on the reference scenario while the average natural gas wells in the US in 2016 produced 132,000 scf per day.

DECC, 2016 notes that median annual demand by UK homes in 2013 was 12,400kwh; equivalent to 393 scf. The result suggests that the wells could supply on a daily basis the annual gas demand of about 3,000 UK homes based on initial production rates. Additionally, over the estimated production period (Figure 7), the eight wells are estimated to produce about $1.1 \mathrm{bcf}$ of gas which can meet the annual 
gas demand of about 2.8 Million UK homes based on 2013 demand data (DECC, 2015) and the central case production scenarios over twelve years.

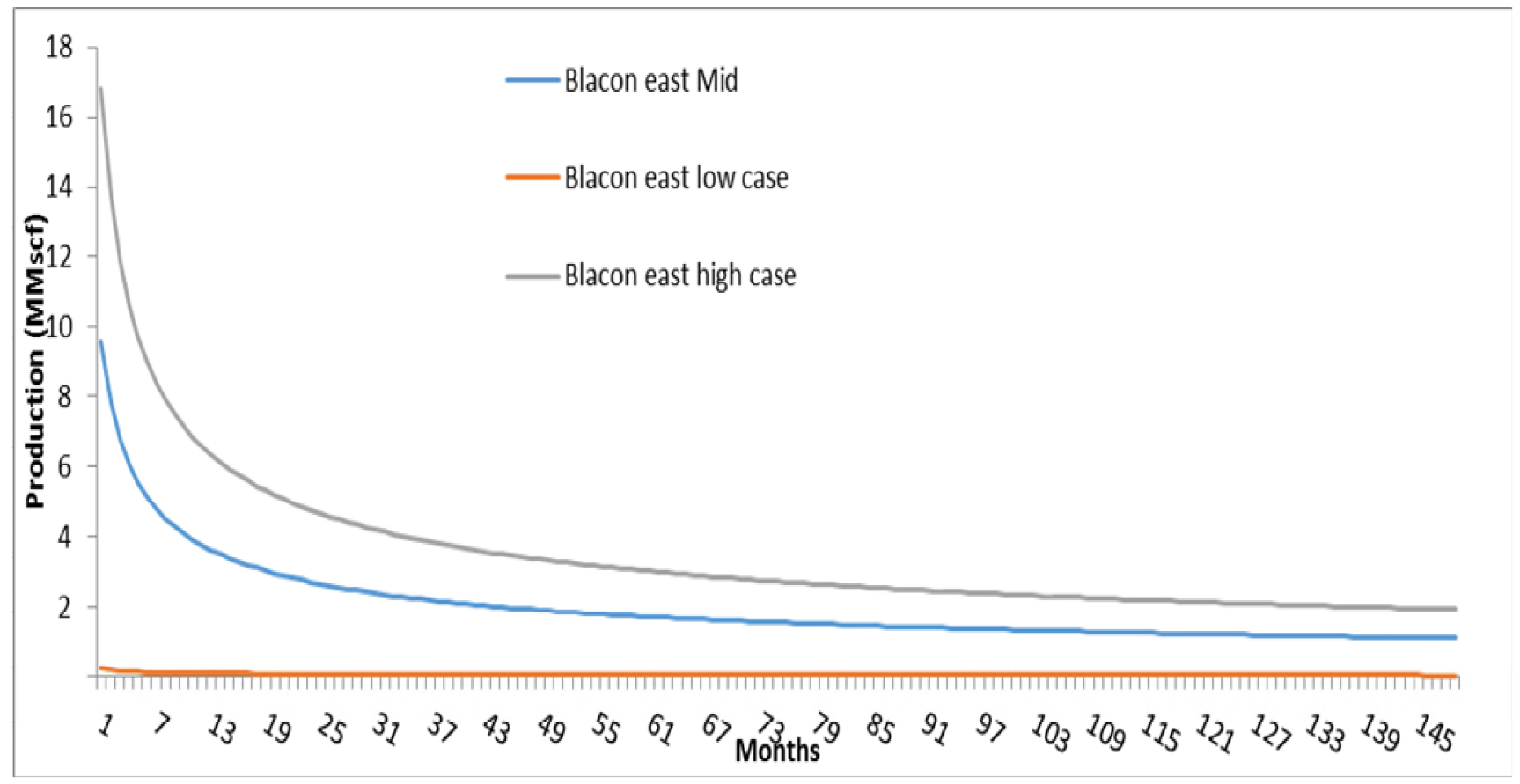

Figure 2 Blacon East Well Production Estimate Profiles

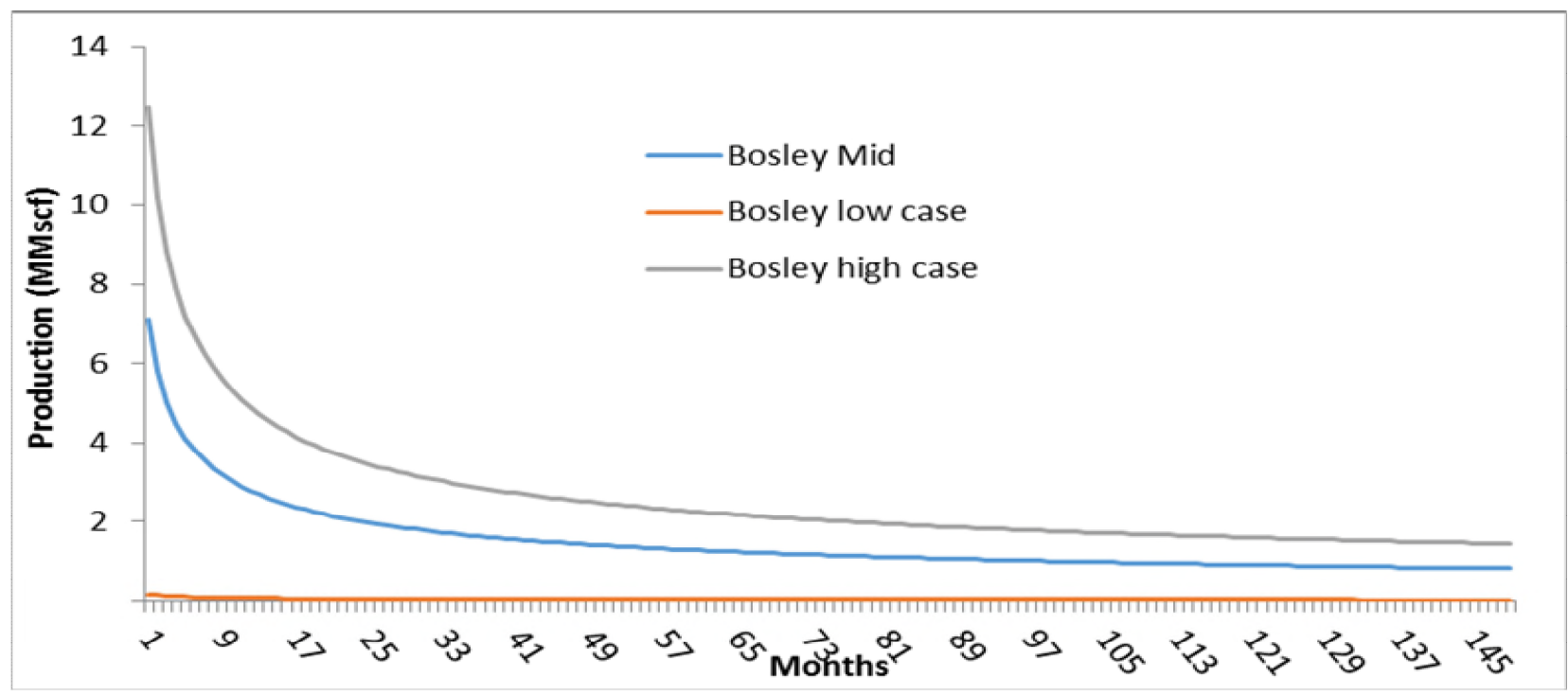

Figure 3 Bosley Well Production Estimate Profiles 


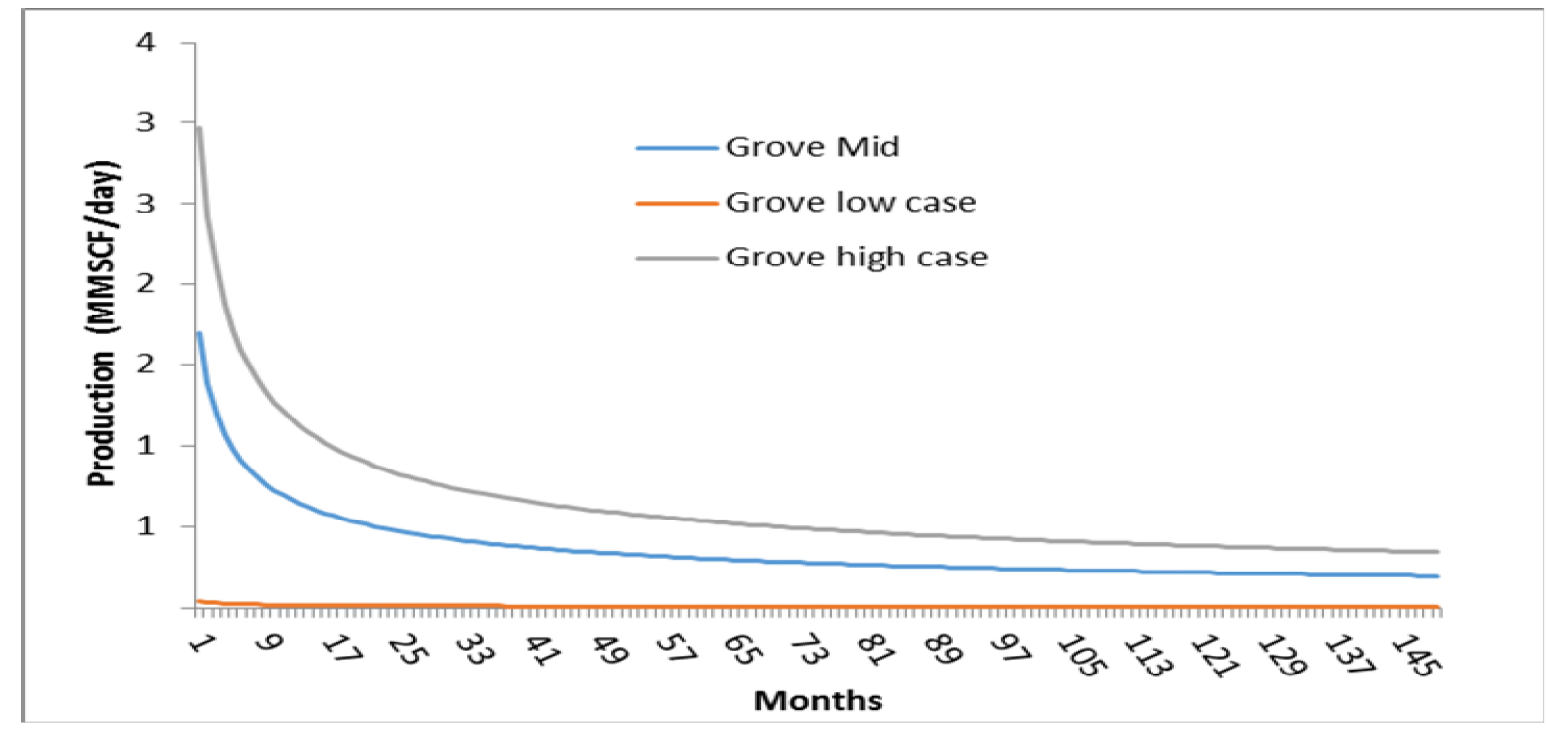

Figure 4 Grove Well Production Estimate Profiles

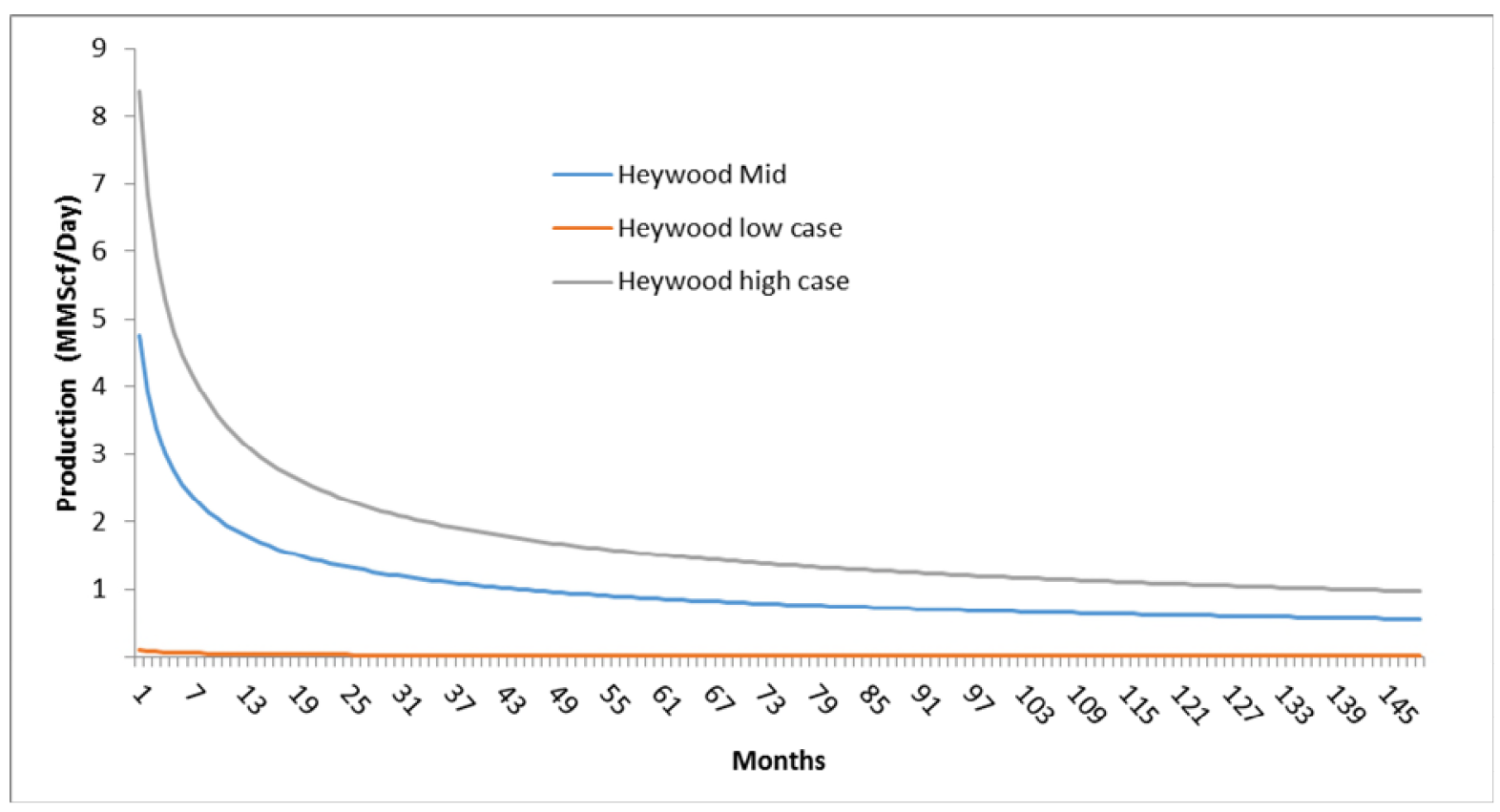

Figure 5: Heywood Well production Profile 


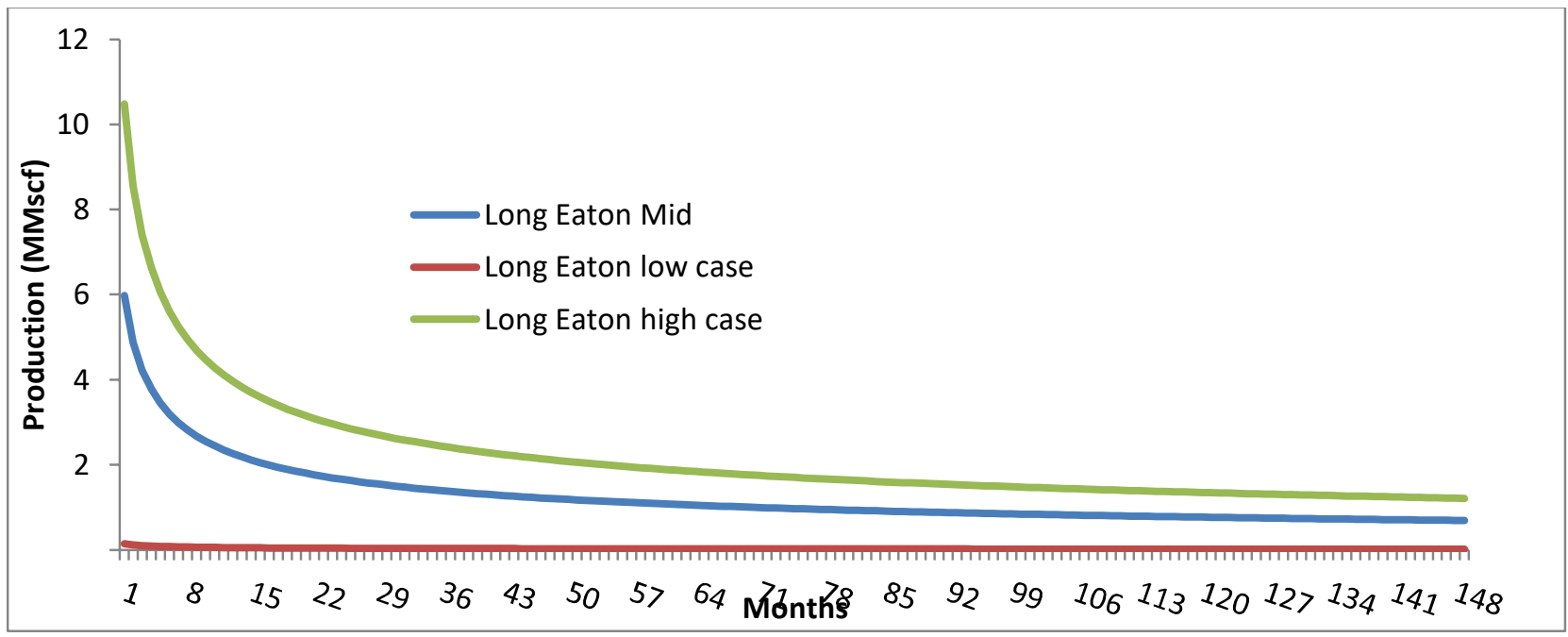

Figure 6 Long Eaton Production Profile

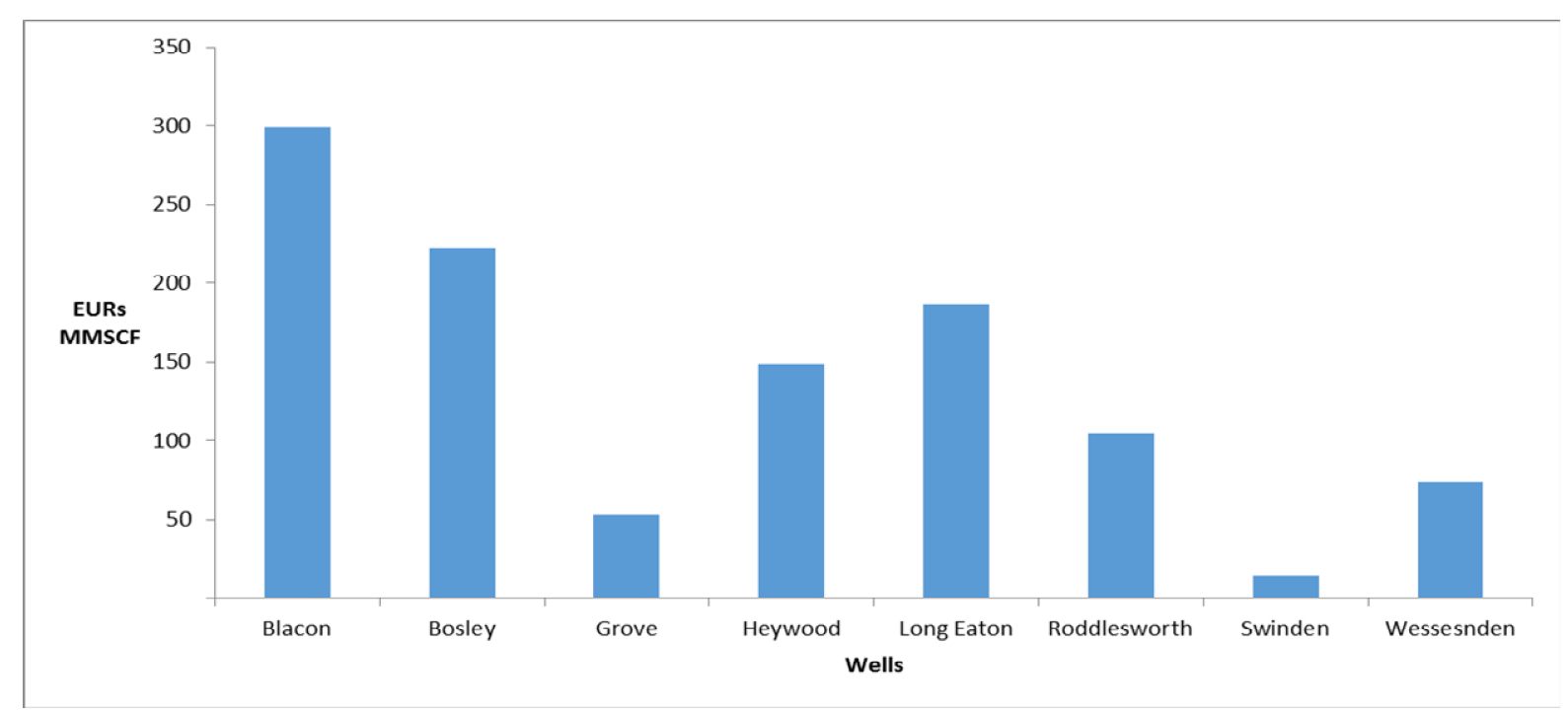

Figure 7 : Estimated Ultimate Recovery over 13 years based on the reference case.

\section{Uncertainty Analysis}

\section{1) Parameter Sensitivity}

The sensitivity of production estimates to uncertainties in below ground/reservoir parameters in terms of production rate was methodically examined. The results in Figure 8 reveals the sensitivity of production rate to estimated input parameters are analysed by varying inputs by + and $-10 \%$ while keeping other parameters unchanged. A $10 \%$ decrease in input values for permeability, porosity and compressibility triggers a $20 \%$ decrease in estimated recovery while a $10 \%$ reduction in the viscosity 
value increases gas recovery by 20\%; an inverse relationship. In the case of the rock extractive index, a $10 \%$ increase in input value results in a $40 \%$ estimated gas recovery growth however for the formation volume factor, a $40 \%$ production decrease yields a $10 \%$ value increase.

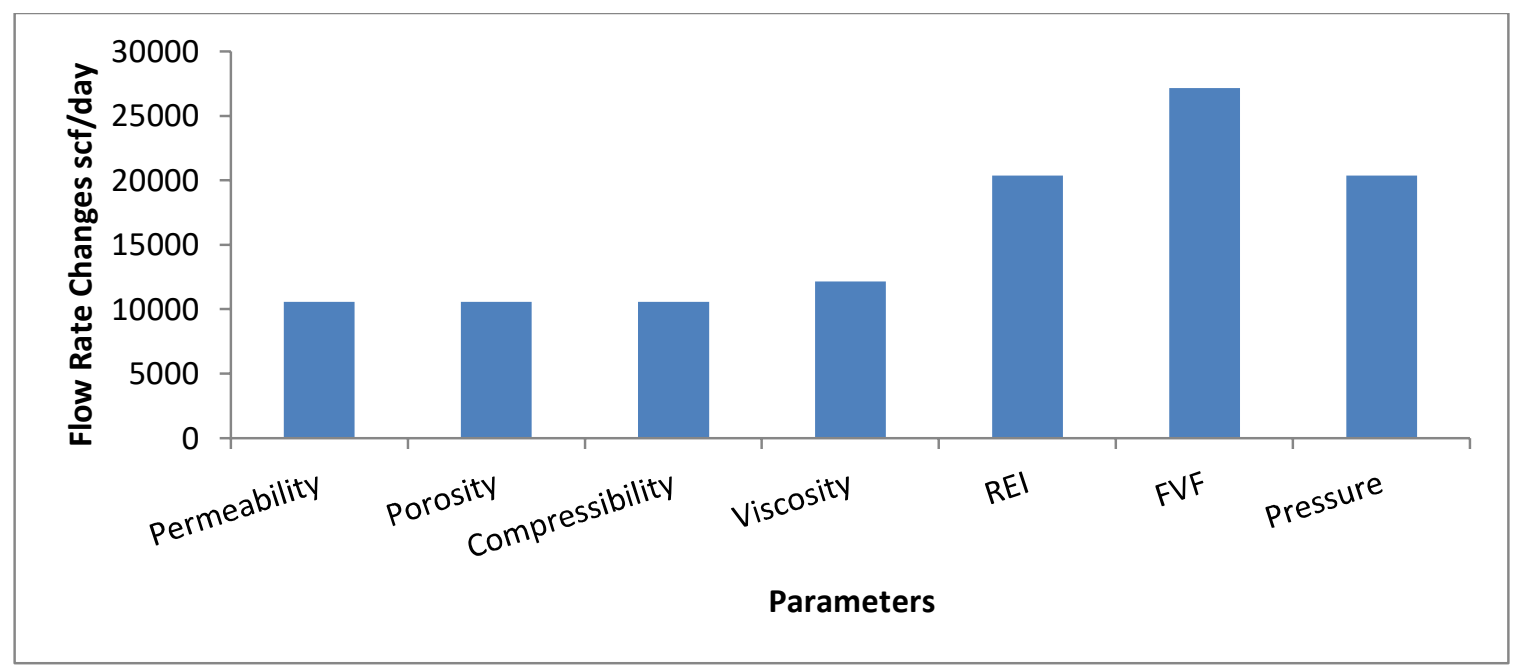

Figure 8 Relative impact of varying parameters (+/-50\%) on initial

Finally, for gas pressure, a 10\% input value increment leads to $40 \%$ increase in estimated production. The results suggest the formation volume factor has the most impact on production estimates, the rock exposure which accounts for the efficiency of the hydraulic fracture process and technology, then pressure and viscosity while permeability, porosity and compressibility have the least and similar impacts. Permeability and porosity which are applied as scenarios due to data unavailability and based on data range in this study have the least impact on recoverable reserve estimation.

The rock exposure identified above as the efficiency of the technology is influenced by reducing the lateral length from an average of $7400 \mathrm{ft}^{3}$ in year 2016 to $3500 \mathrm{ft}^{3}$ for 2013 . This results a reduction in average initial daily production across the eight wells to 73,000scf from 147,150 scf. Consequently the EURs over twelve years also reduce from 1.1 bcf to 549 mmscf. The specific impact on the Blacon east well production profile is revealed in Figure 9 where initial monthly production reduces from $9 \mathrm{mmscf}$ to about $4.5 \mathrm{mmscf}$. The EUR of the Blacon East well consequently also reduces from $299 \mathrm{mmscf}$ to $141 \mathrm{mmscf}$ over the analysed timeframe. 


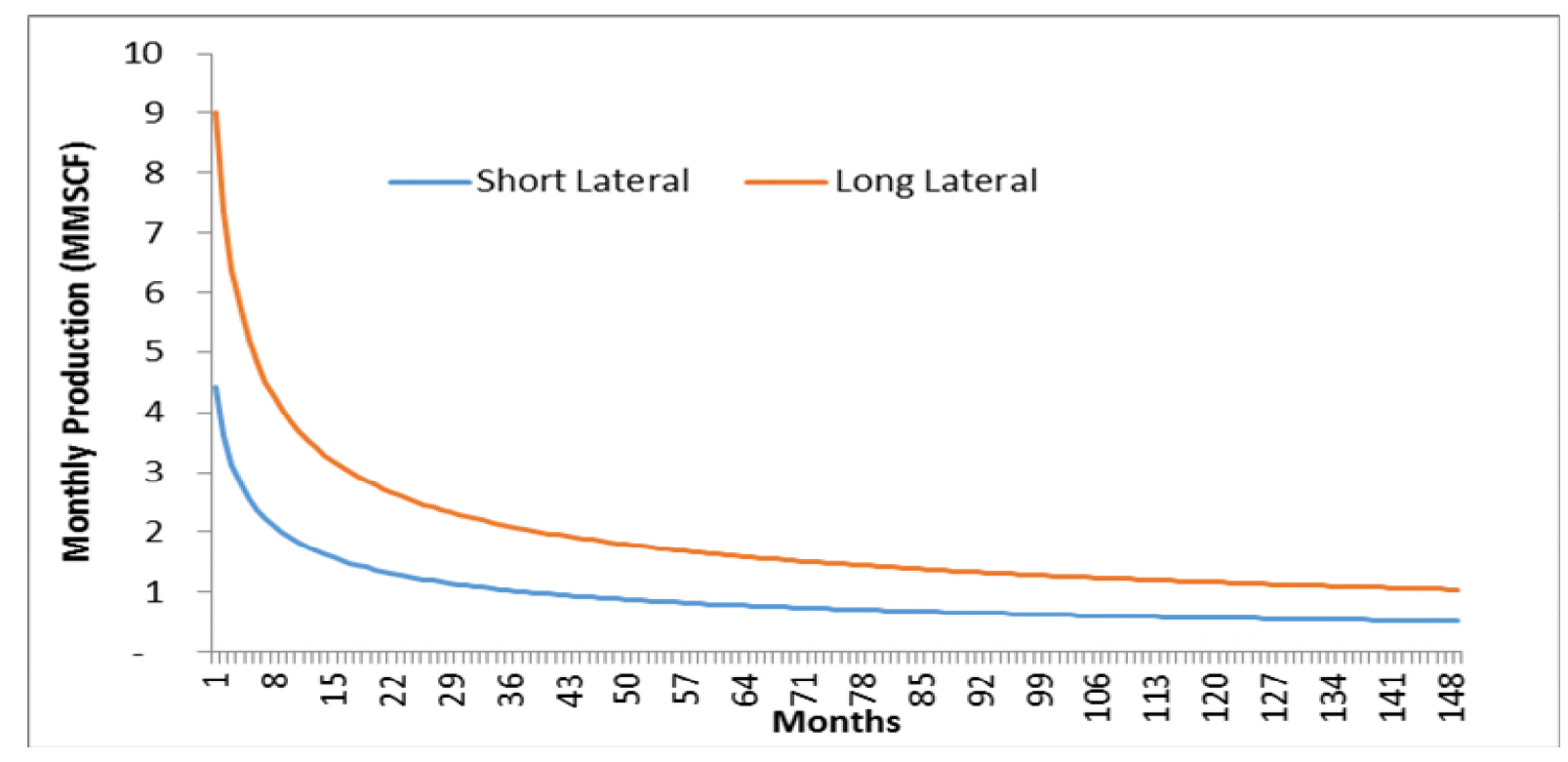

Figure 9 Production Profile of the Blacon East Well with Varying Lateral Lengths

\section{2) Monte Carlo Simulations}

The results of the Monte Carlo simulations which iterate parameters 5 x $10^{3}$ times over 100 simulations for both normal and uniform distributions in relation to permeability and porosity for all wells included in the analysis. The uniform and normal distributions are considered as the current data does not reveal distribution characteristic in the Bowland shale. The uniform distribution scenario assumes that all values within the characteristic ranges for permeability and porosity are assigned an equal possibility of occurrence. Additionally, the normal distribution assumes that about $70 \%$ of observations fall within the mean.

Figure 10 and Figure 11 reveals the most probable permeability and porosity values based on a normal data distribution in the Blacon East Well. The established boundaries for permeability in the Bowland shale by smith et al. (2010) guides the minimum and maximum values applied in the simulation. The simulation's mode and mean for permeability are $3.0038 \times 10^{-3}$ and $3.0 \times 10^{-3}$ while the corresponding results for porosity are 6.5917 and 6.5669. Similar simulation is executed for the other 7 wells in our analysis with the resultant mode values applied in generating production profiles. 


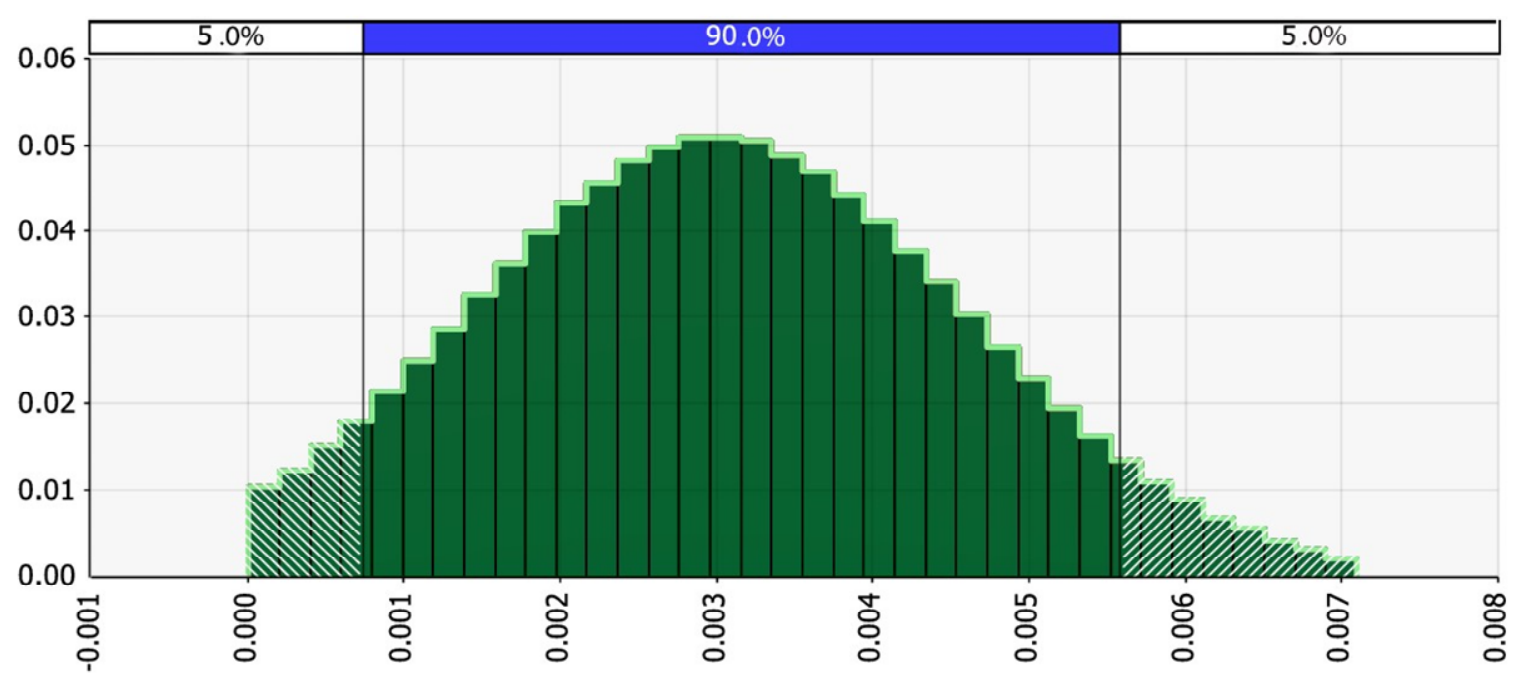

Figure 10 Permeability Summary Trend and Relative Frequency Graphs under Normal Distribution

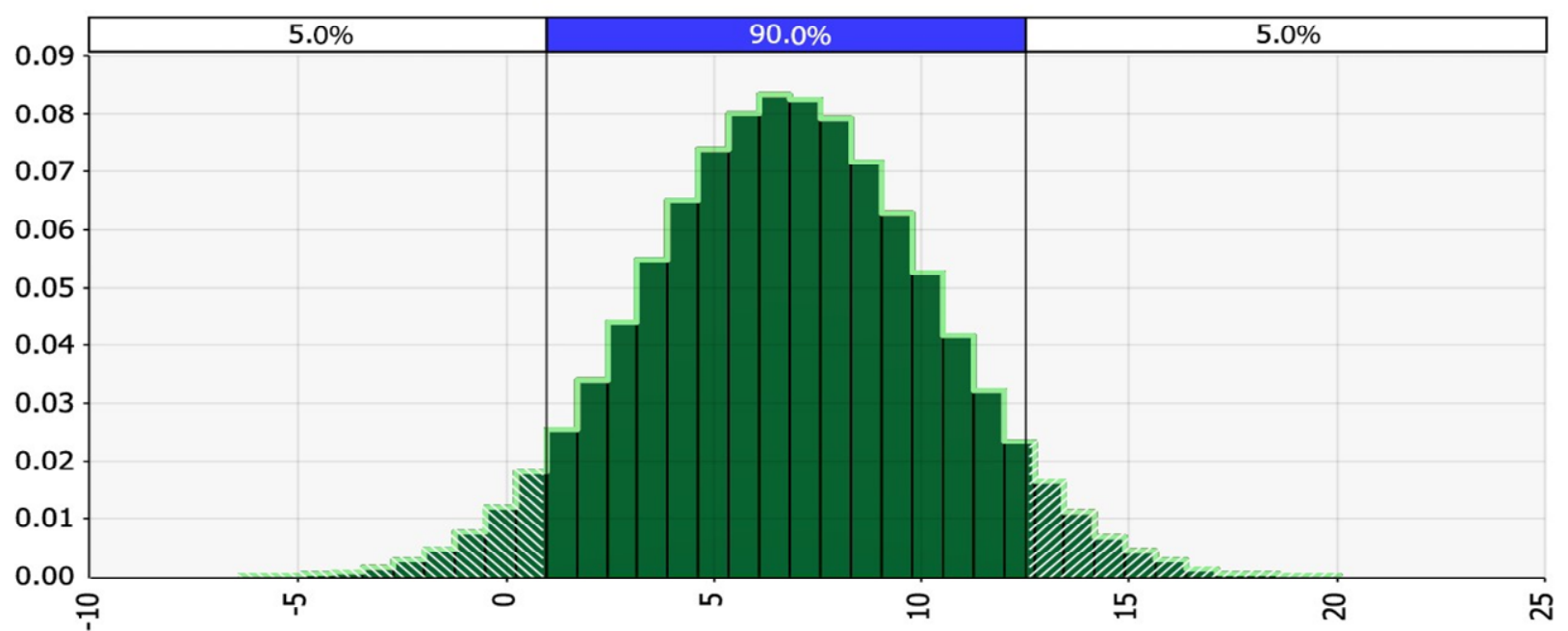

Figure 11 Porosity Summary Trend and Relative Frequency Graphs under Normal Distribution

The results from the uniform distribution simulations for the Blacon East well are revealed in Figures 12 and Figure 13. The mean values for permeability and porosity are $3.0 \times 10^{-3}$ and 6.75 respectively. These resultant parameter values from the simulations are then applied along with the deterministic results from 
DDCM into the numerical model yielding the hybrid scenario. The term hybrid is based on the combination of a deterministic and probabilistic parameter estimation model.

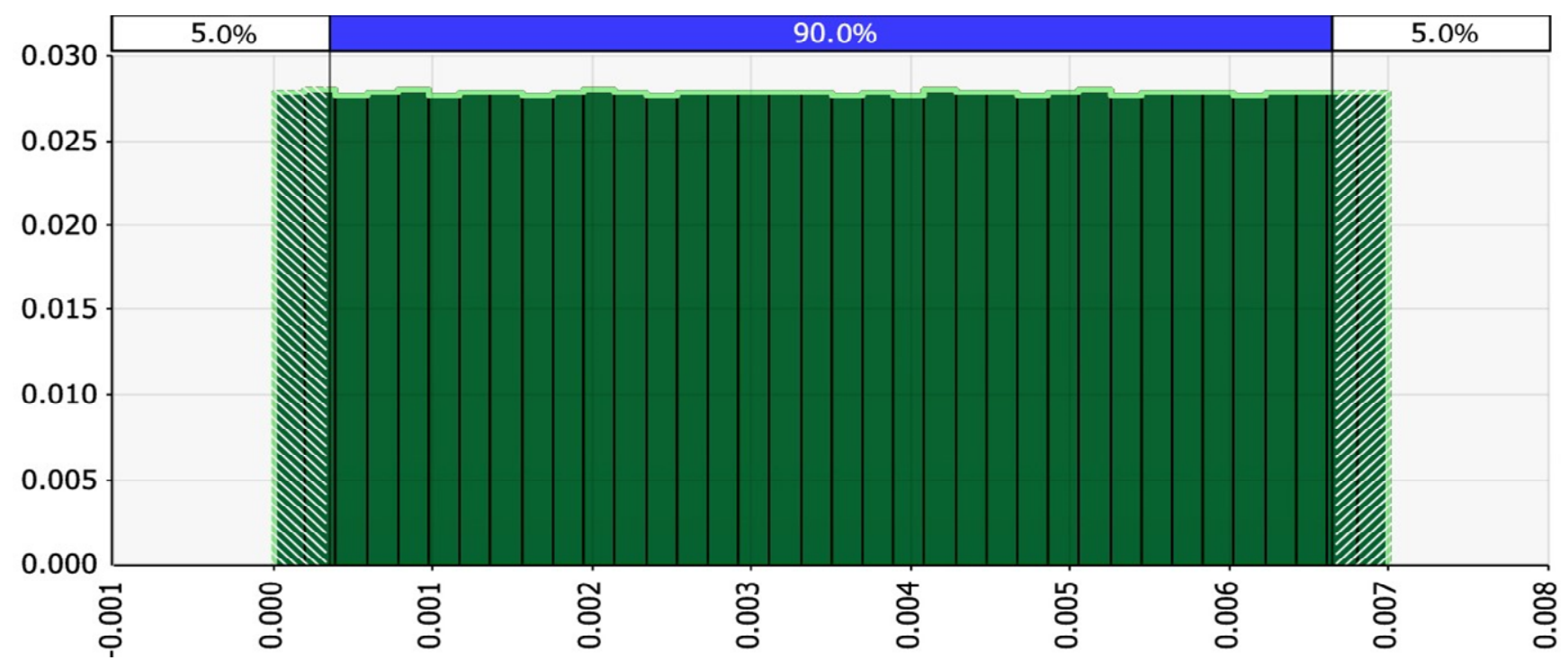

Figure 12 Permeability Summary Trend and Relative Frequency Graphs under Uniform Distribution

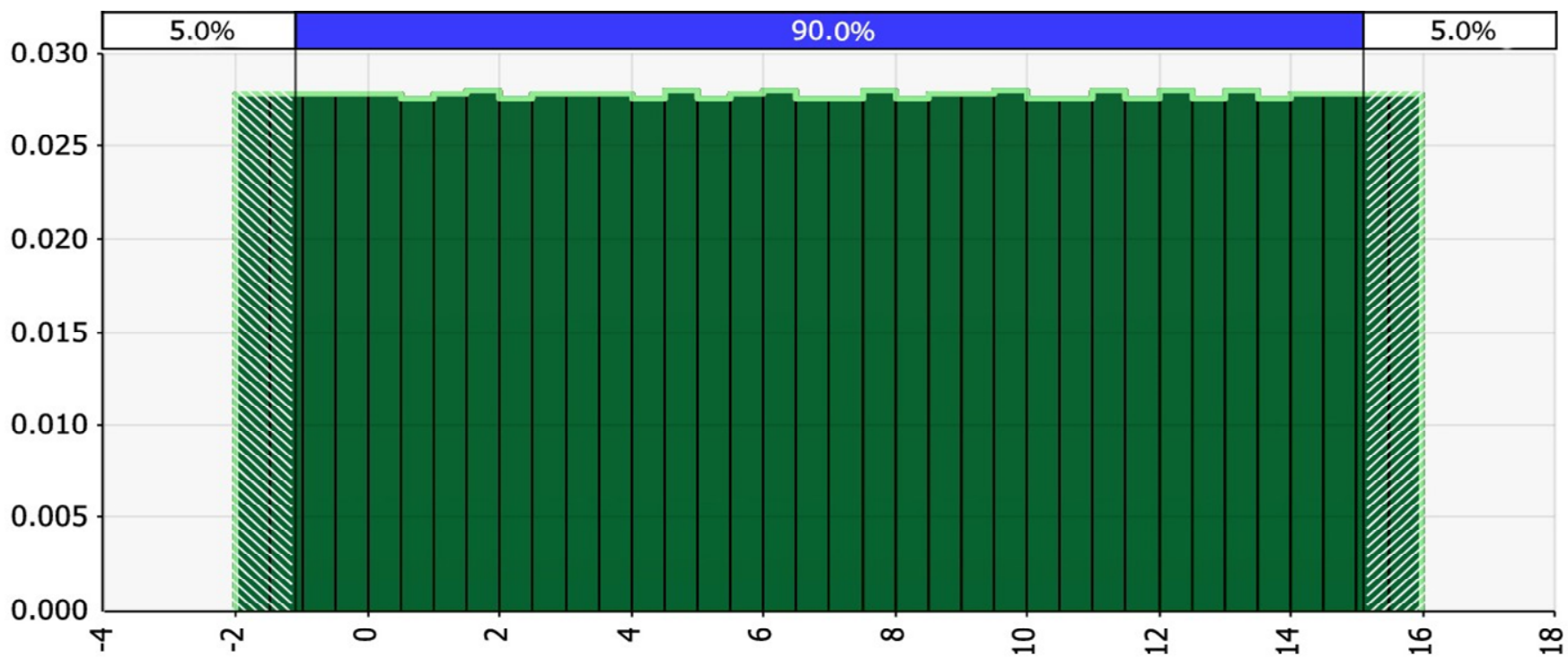

Figure 13 Porosity Summary Trend and Relative Frequency Graphs under Uniform Distribution

\section{Discussion}

The economic appraisal of shale gas reservoirs commences with the estimation of the technically recoverable volume of the gas resource. The technical efficiency of the drilling and hydraulic fracturing technology is a prerequisite to achieving commercial efficiency. Production estimates contribute $67 \%$ of 
uncertainty in economic appraisal of typical shale gas wells (Haskett and Brown, 2010). In Weijeimars 2013 study of the economic appraisal of shale gas plays in continental Europe, significant uncertainty resides in the production estimates based on average EUR/well assumptions on each play. Our approach which incorporates the DDCM enables the estimation of production estimates without reference to assumed averaged estimated recovery or adopted well production values. This study proposes a correlation theory which estimates parameters that impact production in shale gas wells. The results from the correlation model applied to an empirically supported numerical methodology. The technique eliminates the need to apply extrapolated or analogue EURs in production estimation, reduces the production assessment risk while addressing the uncertainty in geological and reservoir parameters.

The resultant production profiles Figures 2-6 are based on scenario and thus boundary parameter values from the novel correlation matrix guided by a review of current literature which provide empirical boundary values as well as model validation. The deterministic approach presents three scenarios while the hybrid (Both Probabilistic and deterministic) provides an alternative production prospect. Sensitivity analysis is essential in shale gas production modelling due to the uncertainty associated with parameters (Zou et al., 2016). The conducted sensitivity analysis establishes the impact of the input parameters on production rate and ultimate recovery. Additionally, the uncertainty degree associated with individual production drivers is ascertained.

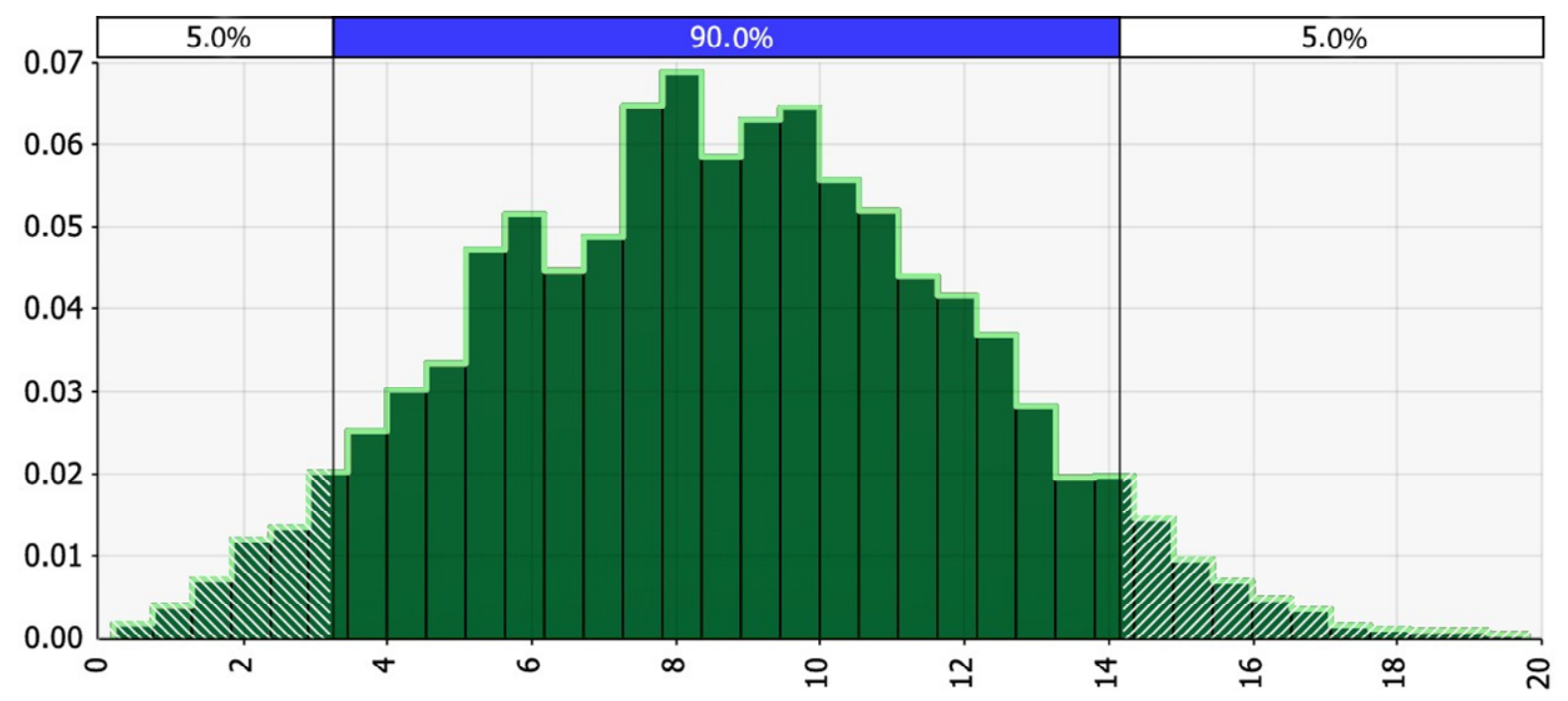

Figure 14 Initial Monthly Production Probability under Normal Distribution Condition for Porosity and Permeability in the Blacon East Well 


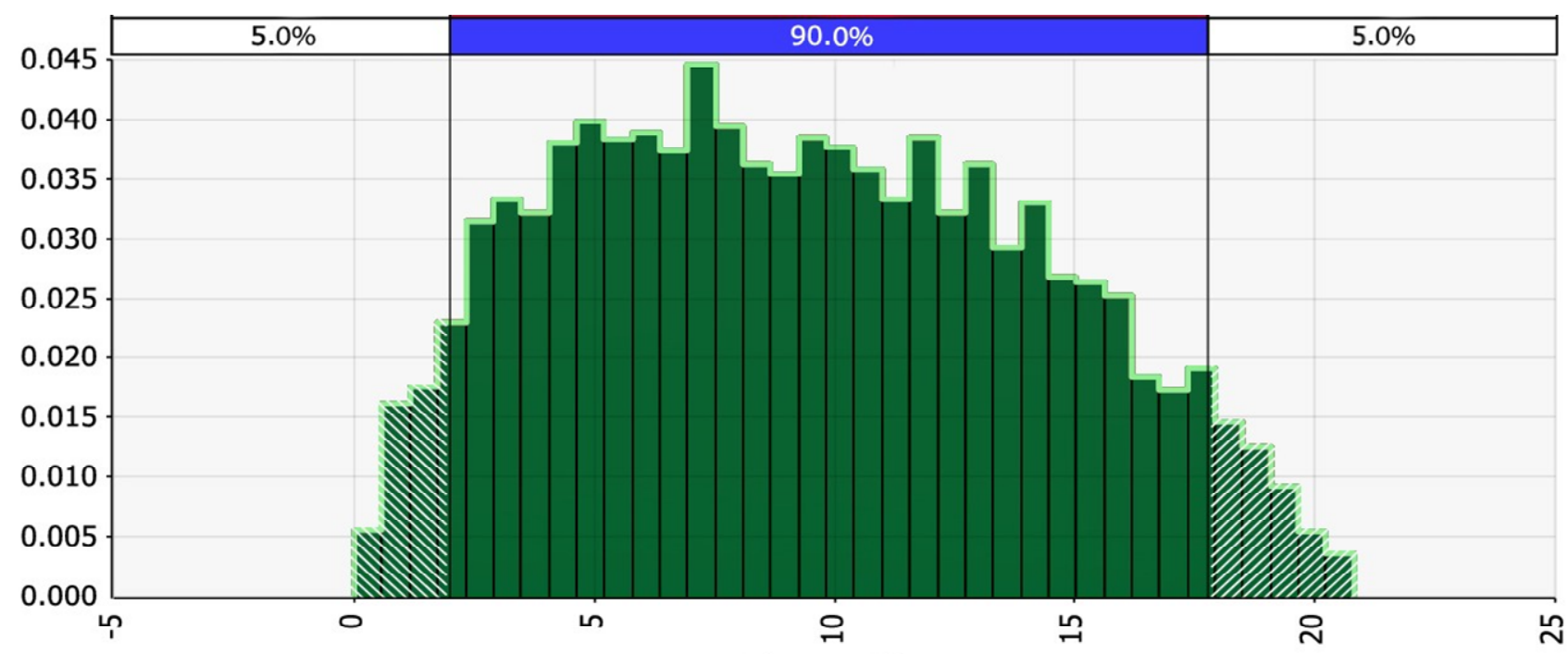

Figure 15 Initial Monthly Production Probability under Uniform Distribution Condition for Porosity and Permeability in the Blacon East Well

A likely shortcoming of the developed modelling approach includes the wide range between the resultant production rates in different scenarios for each well. Consequently, ambiguity in our production appraisal remained primarily due to unavailable porosity and permeability data. However these are addressed by the probable parameters values results from the Monte Carlo simulation in the hybrid case. The resultant production probability profile for the normal and uniform distribution are revealed in Figure 14 and Figure 15, which reveal a most probable monthly production rate of about 9mmscf (normal distribution) and 8.6mmscf (uniform distribution). Figure 16 and Figure 17 show the production profile of 50 iterations in the uniform and normal distribution of parameter scenarios. The uniform parameter derived production profile has an initial monthly production range of $6 \mathrm{mmscf}$ to $11 \mathrm{mmscf}$ while that of the normal distribution scenario is between $6.4 \mathrm{mmscf}$ to $10 \mathrm{mmscf}$.

Additionally, the number of fracture stages and completion strategy gains are not directly considered. Nevertheless, these gains and characteristics all aim to increase the area of fracture. In our model the area of fracture (REI) is conservatively assumed as $1 \%$ of a $7400 \mathrm{ft}^{2}$ lateral length, Zou et al., (2016) applies a minimum value of $6903 \mathrm{~m}^{2}$ equivalent to about $74,303 \mathrm{ft}^{2}$. Further research and clarification is needed to reduce uncertainty in the well specific rock exposure index parameter. However our analysis of this parameter involved the reduction of the lateral length by 3,900 which results on a $50 \%$ reduction in initial production rate.

Overall the modelling framework developed and applied in this study addresses and facilitates production estimation in undeveloped shale gas wells applying the numerical theory. Although the developed and applied method relies upon a lot of specific well data, it provides a more detailed overview of production estimates by accounting for diverse well characteristics. The unique property of wells 
analysed are further revealed by the initial production rates and estimated recovery, with results yielding totally diverse input parameters, rates and recover.

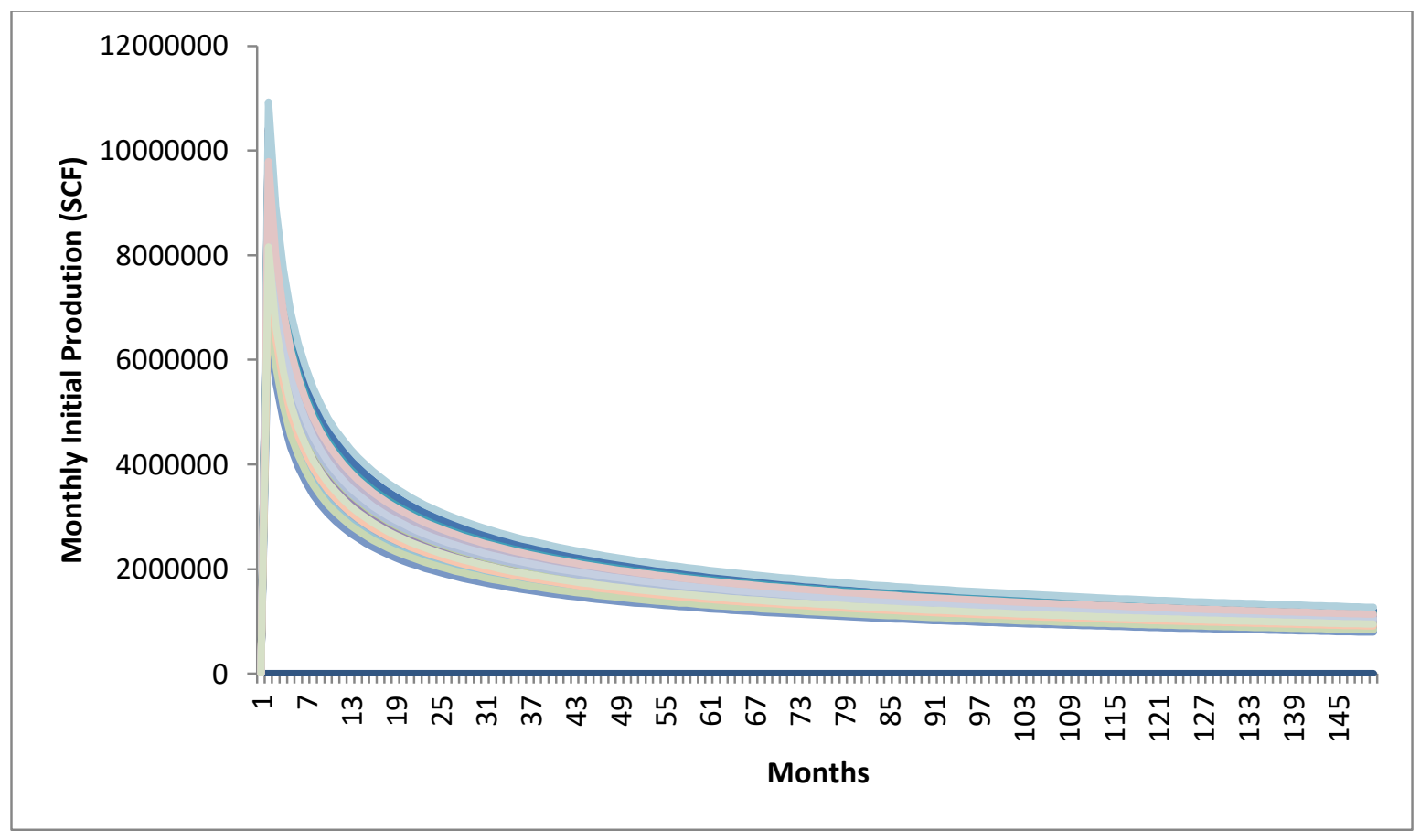

Figure 16 Blacon East Well Production Profile Spread over Iterations guided by Uniform Distributed Parameters

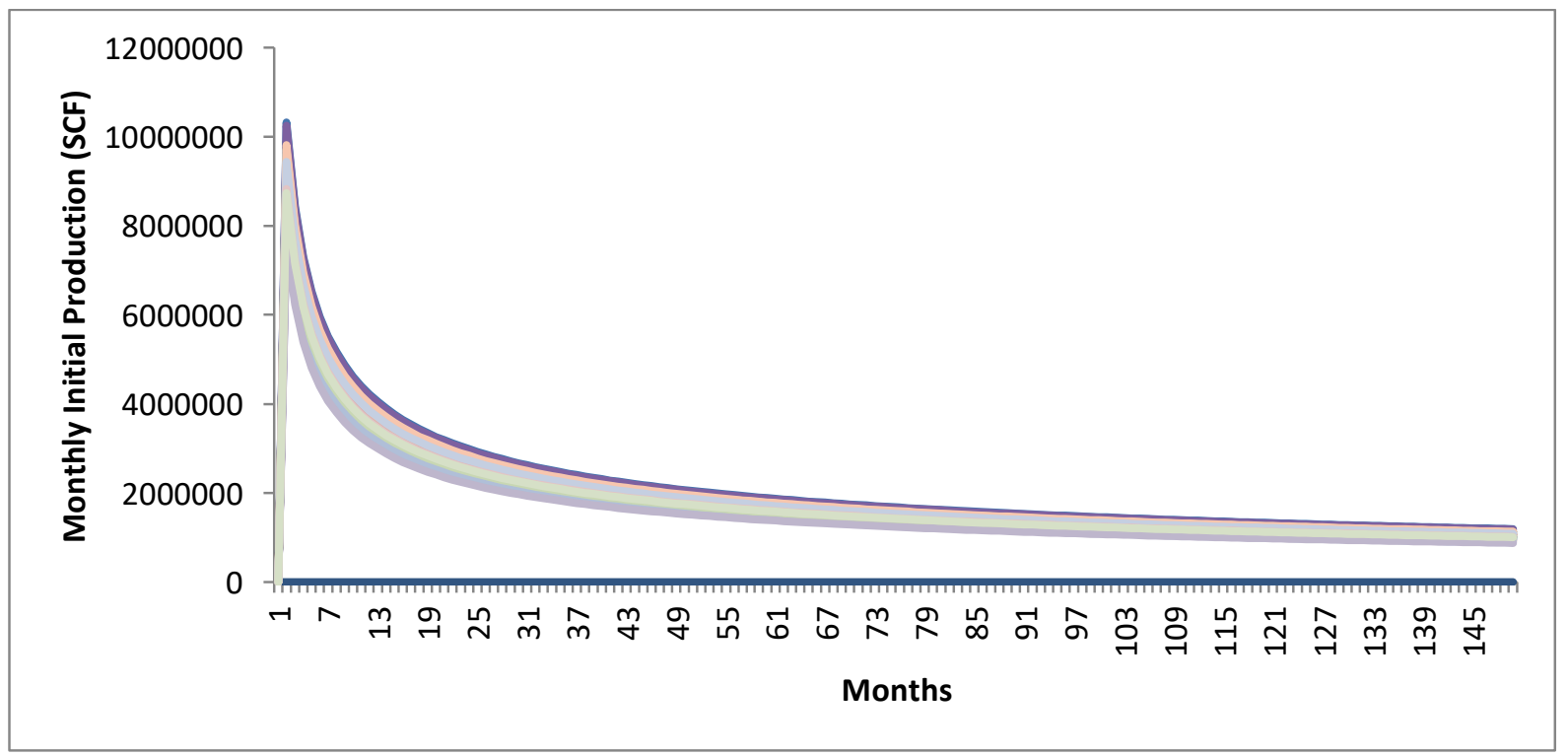

Figure 17 Blacon East Well Production Profile Spread over Iterations guided by Normal Distributed Parameters. 
The results are thus consistent with the positions of McGlade et al., (2013) and USEIA, (2013) both note that empirical evidence suggests the heterogeneous nature of unconventional gas plays even with plays. Cipolla and Ganguly (2012) attribute the heterogeneity to source rock diversity. Most importantly the developed and applied method is based on a per well basis; Gulen et al., (2013) proposes economic evaluation of unconventional gas basins should apply individual well production in economic appraisal. The established method provides a conceptual method to appraise production from undeveloped shale gas wells while recognizing the heterogeneity, below ground uncertainty and identifies probable high production wells (Sweet Spots) within a prospective play.

\section{Conclusions}

This study applies the numerical theory in shale gas production modelling; scenarios based on possible ranges and their median value which can be equated to P10, P50, P90 used in conventional gas production economic appraisal are developed based on input parameter value. A further probabilistic scenario is generated with the Monte Carlo simulation. The data range from porosity and permeability in addition to results from the input parameter estimation are integrated into the numerical model to reveal production profiles in the Bowland Shale in Britain based on scenarios. This method provides an alternate to the current empirical and type curve practice which rely on average EURs and initial production data from analogous shale wells/play for undeveloped shale wells.

The Bowland shale case study shows that the eight wells developed and modelled conservatively can produce an average of 147,00 scf natural gas daily while the EUR over 12 years is estimated as $1.1 \mathrm{bcf}$ of natural gas. Sensitivity analysis shows that the production is highly sensitive to these parameters (Rock Exposure based on technology efficiency, Reservoir Pressure and the formation volume factor). Moreover based on the 50\% increase in possible production within three years (2013 -2016), delay in well development has indeed enhanced the commercial viability of future potential wells.

The study infers that an economic model supported with an appopriate production estimation model will provide proper guidiance to policy makers and investors. The estimation of gas production from the modeling approach developed in this study and applied to the Bowland shale play can be integrated into an economic model to provide policy guidiance. However futher quantitative studies on the porosity and permeability properties of the source rock will reduce uncertainty in the production estimates. Expolratory drilling will provide the rock samples and thus a precise porosity and permeability data. Finally, the uncertainty in relation to cyclical gas prices, regulation , cost of development as well 
as relevant energy policy in relation to undeveloped shale gas plays need to be appraised to aserctain their impact on field development planning and thus commercial viability.

\section{References}

AEA. (2012). Climate impact of potential shale gas production in the EU report for European Commission DG CLIMA. London: AEA/DG CLIMA European Commission.

Agrawal, R., Gardner, D., Kleinsteiber, S., \& Fussell, D. (1999). Analyzing Well Production Data Using Combined-Type Curve and Decline Type Curve Analysis Concept. 1998 SPE Annual Technical Conference and Exhibition. New Orleans: SPE.

Anandarajah, G., \& Nwaobi, U. (2018). A Critical Review of Unconventional Gas Production Analysis and Estimation Methods. UCL, In Press.

Andrews, I. (2013). The Carboniferous Bowland Shale gas study: geology and resource estimation. London: British Geological Survey for Department of Energy and Climate Change.

Arps, J. (1944). Analysis of Decline Curves. AIME, 228-247. 945228.

Baihly, J., Altman, R., Malpani, R., \& Luo, F. (2010). Shale Gas production Decline Trend Comparison Over Time and Basins. SPE Annual Technical Conference and Exhibition. Florence, Italy: SPE 135555.

Bingxiang, Lu, M., Haghihi, X., Li, C., \& Dennis. (2013). Development of New Type Curve for Production Analysis in Naturally Fractured Shale Gas/Tight Gas Reserviors. Juornal of Petroleum Science \& Engineering, 107-115.

Blasingame, T., \& Palacio, J. (1993). Decline Curve Analysis using Type Curve- Analysis of Gas Well Production Data. SPE Joint Rocky Mountain Regional and Low Pearmeabiltiy Reservior Symposium (p. SPE 25909). Denver: SPE.

Browning, J., Tinker, S. W., Ikomikova, S., Gulen, G., Potter, E., Fu, Q., et al. (2013). Barnet Study Determines Full Field Reserves, Production Forecast. Oil and Gas Journal, Barnet Shale Model 2.

Cander. (2012). Sweet Spots in Shale Gas \& Liquids Play: Prediction of Fluid Composition and Reservior Pressure. AAPG Annual Conference \& Exhibition. Long Beach, California: AAPG.

Chen, Z., Osadetz, K., \& Chen, X. (2015). Economic Appraisal of Shale Gas Resources; An Example from The Horn River Shale Gas Play, Canada. Journal of Petroleum Science, 12: 712-725.

Cipolla, C. L., Lolon, E. P., Erdle, J. C., \& Rubin, B. (2010). Reservoir Modeling in Shale-Gas Reservoirs. . Society of Petroleum Engineers., doi:10.2118/125530-PA.

Cipolla, C., \& Ganguly, U. (2012). Multi Domain Data and Modelling Unlock Unconventional Resource Challenges. Journal of Petroleum Technology.

Clark, A. J. (2011). Decline Curve Analysis in Unconventional Resource Plays Using Logistic Growth Models . Austin: MSc Thesis Presented to the Faculty of the Graduate School of The University of Texas at Austin .

Clarkson, C. (2013). Production Analysis of Unconventional Gas Wells: Review of Theory and Best Practices. International Journal of Coal Geology, 109-110 (101-146).

Clarkson, C., Jensen, J., \& Chipperfield. (2012). Unconventional Gas Reservior Evaluation: What do we have to consider? Journal of Natural Gas Science and Engineering, 9-33.

Considine, T., Watson, R., \& Blumsack, S. (2010). The Economic Impacts of the Pennsylvania Marcellus Shale Natural Gas Play: An Update. Pennsylvannia: The Pennsylvannia State University.

Considine, T., Watson, R., \& J, S. (2009). An Emerging Giant: Prospects and Economic Impacts of Developing the Marcellus Shale Natural Gas Play. Pennsylvania: The Pennsylvania State University.

Curtis, J. (2002). Introduction to unconventional petroleum systems:. AAPG Bulletin, v. 86, p. 1851-1852. 
Dake, L. (1998 Seventeenth Impression). Fundamentals of Reservior Engineering. Amsterdam: ELSEVIER SCIENCE B.V. .

DECC . (2013). About Shale Gas and Hydraulic Fracturing. London: The Department of Energy and Climate Change.

DECC. (2013b). Onshore Oil and Gas Exploration in the UK: Regulation and Best Practice. London: Department of Energy of Climate Change.

DECC. (2015). Nationaly Energy Efficiency Data Framework "NEED". London: Department of Energy and Climate Change.

Department of Energy and Climate Change (DECC). (2011). The Unconventional Hydrocarbon Resources of Britain's Onshore Basin-Shale Gas. London: DECC.

Durst, F. (2008). Fluid Mechanics: An Introduction to the Theory of Fluid Flows. Erlangen, Germany: Springer.

Eker, S., \& Daalen, E. v. (2012). Uncertainties in the Development of Unconventional Gas in the Netherlands. Jaffalaan: Delft University of Technology.

Fetkovich, M. (1980). Decline Curve Analysis Using Type Curves. Journal of Petroleum Technology, (6) 637-656.

Fetkovich, M., \& Fetkovich, E. (1996). Useful Concepts for Decline Curve Forecasting, Reserve Estimation and Analysis. SPE Reservior Engineering, Vol 11 pages 13-22.

Fetkovich, M., Vienot, M., Bradley, M., \& Klosow, U. (1987). Decline Curve Analysis Using Type Curves. SPE Annual Technical Conference \& Exhibition. Houston: SPE.

Geny, F. (2010). Can Unconventional Gas be a Game Changer in European Gas Markets? Oxford: The Oxford Institute For Energy Studies.

Gray, W., Hoefe, T., Chiappe, A., \& Koosh, V. (2007). A Probabilistic Approach to Shale Gas Economics. SPE Hydrocarbon Economics and Evaluation Symposium (p. SPE 108053). Dallas, Texas: SPE.

Gross, D., Sachsenhofer, R., Bechtel, A., Pytlak, L., Rupprecht, B., \& Wegerer, E. (2015). Organic Geochemistry of Mississippian Shales (Bowland Shale Formation) in Central Britain: Implications For Depositional Environment, Source Rock and Gas Shale Potential. Marine and Petroleum Geology, Volume 59, January 2015, Pages 1-21.

Guarnone, M., Rossi, F., Negni, E., Grassi, C., Genazzi, D., \& Zennaro, R. (2012). An Unconventional Mindset for Shale Gas Surface Facilities. Journal of Natural Gas Science and Engineering, Vol 6 14-23.

Gulen, G. G., Tinker, S., Ikonnikova, S., \& Browning, J. (2014). Fayetteville Shale-Production Outlook. Society of Petroleum Engineers. , doi:10.2118/173187-PA.

Gulen, G., Browning, J., Ikonnikova, S., \& Tinker, S. (2013). Well Economics Across Ten Tiers in Low and BTU Areas, Barnett Shale, Texas. Energy, 302-315.

Hahn, R. (2010). Designing Smarter Regultion with Improved Benefits-Cost Analysis. Journal of BenefitsCost Analysis, 5.

Hammond, G. P., \& O Grady, A. (2016). Indicative Energy Technology Assessment of UK Shale Gas Extraction. Applied Energy, In Press.

Haskett, W., \& Brown, P. (2010). Pitfalls in the Evaluation of Unconventional Resources. SPE Annual Technical Conference and Exhibition, 19-22 September (pp. DOIhttp://dx.doi.org/10.2118/135208MS). Florence: SPE 135208-MS.

HoL, H. o. (2014). The Economic Impact on UK Energy Policy of Shale Gas \& Oil. London: Economic Affairs Committee.

Holditch, S. (2013). "Unconventional oil and gas resource development - Let's do it right". Journal of Unconventional Oil and Gas Resources, vol. 1-2, pp. 2-8.

Ilk, D., Mattar, L., \& Blasingame, T. (2007). Production Data Analysis- Future Practices for Analysis and Interpretation. 8th Canadian International Petroleum Conference (p. 174). Alberta: Canadian Institute of Mining, Metallurgy and Petroleum. 
Ilk, D., Rushing, J., Perego, A., \& Blansingame, T. (2008). Exponential Vs Hyperbolic Decline in Tight Sands-Understanding the Origin and Implications for Reserve Estimation Using Arps Decline Curves. SPE Annual Technical Conference and Exhibition (p. SPE 116731). Denver, Colorado: Society Petroleum Engineers.

Johnson, C., \& Boersma, T. (2013). Energy (in) Securitynin Poland the Casebof Shale Gas. Energy Policy, 53,389-399.

Kaiser, M. (2012). Haynesville Shale Play Economic Analysis. Journal of Petroleum Science and Engineering, 82-83 (2012) 75-89.

Kanfar, M. (2013). Comparison of Empirical Decline Analysis for Shale Wells (MSc Thesis). Texas: Texas A\&M.

Knudsen, B. R. (2010). Production Optimization in Shale Gas Reserviors (Msc Thesis). Trondheim: Norwegian University of Science and Technology .

Krupnick et al. (2013). A Retrospective Review of Shale Gas Development in the United States. Washington DC: Resources For the Future.

Kuhn, M., \& Umbach, F. (2011). Strategic Perspectives of Unconventional Gas: A Game Changer with Implications for the EU's Energy Security. London: European Centre for Energy and Resource Security, King's College London.

Lee, D., Herman, J., Elsworth, D., Kim, H., \& Hyun, L. S. (2011). A Critical Evaluation Of Unconventional Gas Resources From the Marcellus Shale, Northeastern, United States. Journal of Civil Engineering, 679-687.

Lee, J., Rollins, J., \& Spivey, J. (2003). Pressure Transient Testing. Richardson: SPE Textbook Series 9.

Lee, W., \& Sindle, R. (2010). Gas Reserve Estimation in Resource Plays. SPE Unconventional Gas Conference. Pittsburgh,Pennsylvania: SPE.

Lide, D. (2005). CRC Handbook of Chemistry and Physics. Boca Raton: CRC Press LLC.

Mc Cain, W. (1990). The Properties of Petroleum Fluids. Oklahoma: PennWell.

McGlade, C. (2013). Uncertainties in the outlook for oil and gas. London: PhD Thesis, Energy Institute, UCL.

McGlade, C., Speurs, J., \& Sorrell, S. (2013). Unconventional Gas-A Review of Regional and Global Resource Estimates. Energy, 571-584.

Medlock, K. (2012). Panel Data Analysis of Well Production History in the Barnet Shale. 31st Annual USAEE/IAEE North American Conference. Austin: USAEE/IAEE.

Middleton, R., Carey, W. J., Currier, J. D., Kang, Q., Karra, S., Jimenez-Martinez, J., et al. (2015). Shale Gas and Non-Aquenous Fracturing Fluids: Opportunities and Challenges for Supercritical CO2. Applied Energy, 500-509.

Nobakht, M., Mattar, L., Moghadam, S., \& Anderson, D. (2012). Simplified Forecasting of Tight/Shale Gas Production in Linear Flow. Journal of Canadian Petroleum Technology, 51 (6): 476-486. SPE 133615-PA.

Patzek, T., Marder, M., \& Male, F. (2013). Gas Production in the Barnett Shale obeys a Simple Scaling Theory. Proceedings of the National Academy of Sciences of the United States.

Pearson, I., Zeniewski, P., Gracceva, F., Zastera, P., McGlade, C., Sorrell, S., et al. (2012). Unconventional Gas: Potential Energy Market Impacts in the European Union. A Report by the Energy Security Unit of the European Commission's Joint Research Centre. Luxembourg: Office of the European Union.

Selley, R. (1987). British Shale Gas Potential Scrutinized. Oil and Gas Journal, June 15, pp62-64.

Selley, R. (1992). Petroleum Seepages and Impregnation in Great Britain. Marine and Petroleum Geology, 9(3) 225-328.

Selley, R. (2005). UK Shale Gas Resources In: Dore A.G Vining, B.A (Eds) Petroleum Geology: North Western Europe and Global Perspective. 6th Petroleum Geology Conference (pp. 707-714).

London: Geological Society London.

Selley, R. (2011). UK shale gas: The story so far. Marine and Petroleum Geology, 31 (2012) 100-109. 
Sepehrnoor, K., Tavassoli, S., \& Javadpour, F. (2013). Well Screen \& Optimal Time of Refracturing: A Barnet Shale Well. Journal of Petroleum Engineering, 817293.

Smith, N., Turner, P., \& Williams, G. (2010). UK Data and Analysis for Shale Gas Prospectivity. Proceedings of the 7th Petroleum Geology Conferences (pp. v7;p1087-1098). London: Geological Society London.

Statton, J. C. (2012). Application of the Strectched Exponential Decline Medel to Forcast Production in Shale Gas Reserviors (MSc Thesis). Texas: Texas A\&M.

Taylor, C. (2013). Getting Shale gas Working. London: Institute of Directors.

USEIA. (2013). Technically Recoverable Shale Oil and Shale Gas Resources: An Assessment of 137 Shale Formations in 41 Countries Outside the United States. Washington: Energy Information Administration.

USEIA. (2013). World Shale Gas and Shale Oil Assessment. Arlington: United States Energy Information .

USEIA. (2016). Trends in U.S. Oil and Natural Gas Upstream Costs. Washington D.C.: U.S. Department of Energy.

USEIA. (2017). The Distribution of U.S. Oil and Natural Gas Wells by Production Rate. Washington, DC: U.S Department of Energy.

Valko, P., \& Lee, W. (2010). A Better Way to Forecast Production From Unconventional Gas Wells. SPE Annual Technical Conference and Exhibition (p. SPE 134231). Florence: Society of Petroleum Engineers.

Vera, F., \& Ehlig-Economides:, C. (2014). Describing Shale Well Performance Using Transient Well Analysis. Texas.

Wang:, C. (2013). PRESSURE TRANSIENT ANALYSIS OF FRACTURED WELLS IN SHALE RESERVOIRS. Colorado: MSc Thesis Colorado School of Mines.

Wattenbarger, R., El-Banbi, R., Villegas, A., \& Maggard, M. (1998). Production Analysis of Linear Flow into Fractured Tight Gas Wells. SPE Rocky Mountain Regional/Low Permeability Reserviors Symposium (p. SPE 39931). Denver: SPE.

Weijermars, R. (2013). Economic Appraisal of Shale Gas Plays in Continental Europe. Applied Energy, $100-115$.

Weijermars, R. (2014). Shale Gas Technology Innovation Rate Impact on Economic Base Case-Scenarios Model Benchmark. Applied Energy, 398-407.

Weijermars, R. (2014). US Shale Gas Production Outlook based on Well Roll-Out rate Scenarios. Applied Energy, 283-297.

Williams-Kovacs, J., \& Clarkson, C. (2011). Using Stochastic Simulation To Quantify Risk and Uncertainty in Shale Gas Prospecting and Development. Canadian Unconventional Resources Conference (p. CSUG/SPE 148867 ). Calgary, Alberta: Society of Petroleum Engineers.

Yuan, J., Luo, D., \& Feng, L. (2015). A Review of the Technical and Economic Evaluation Techniques for Shale Gas Development. Applied Energy, 49-65.

Zou, Y., Yang, C., Wu, D., Yan, C., Zeng, M., Lan, Y., et al. (2016). Probabilistic Assessment of Shale Gas Production and Water Demand. Applied Energy, 185-195. 